\title{
A comparison of GC-FID and PTR-MS toluene measurements in ambient air under conditions of enhanced monoterpene loading
}

\author{
J. L. Ambrose ${ }^{1,2}$, K. Haase ${ }^{1,2}$, R. S. Russo ${ }^{2}$, Y. Zhou ${ }^{2}$, M. L. White ${ }^{2, *}$, E. K. Frinak ${ }^{2, * *}$, C. Jordan ${ }^{2}$, H. R. Mayne ${ }^{1}$, \\ R. Talbot ${ }^{2}$, and B. C. Sive ${ }^{2}$ \\ ${ }^{1}$ Department of Chemistry, University of New Hampshire, Durham, New Hampshire, USA \\ ${ }^{2}$ Climate Change Research Center, Institute for the Study of Earth Oceans and Space, University of New Hampshire, Durham, \\ New Hampshire, USA \\ * now at: Northern Essex Community College, Haverhill, Massachusetts, USA \\ ** now at: USMA Network Science Center, West Point, New York, USA
}

Received: 17 November 2009 - Published in Atmos. Meas. Tech. Discuss.: 6 January 2010

Revised: 22 May 2010 - Accepted: 16 June 2010 - Published: 23 July 2010

\begin{abstract}
Toluene was measured using both a gas chromatographic system (GC), with a flame ionization detector (FID), and a proton transfer reaction-mass spectrometer (PTR-MS) at the AIRMAP atmospheric monitoring station Thompson Farm (THF) in rural Durham, NH during the summer of 2004. Simultaneous measurements of monoterpenes, including $\alpha$ - and $\beta$-pinene, camphene, $\Delta^{3}$-carene, and $d$-limonene, by GC-FID demonstrated large enhancements in monoterpene mixing ratios relative to toluene, with median and maximum enhancement ratios of $\sim 2$ and $\sim 30$, respectively. A detailed comparison between the GC-FID and PTR-MS toluene measurements was conducted to test the specificity of PTR-MS for atmospheric toluene measurements under conditions often dominated by biogenic emissions. We derived quantitative estimates of potential interferences in the PTR-MS toluene measurements related to sampling and analysis of monoterpenes, including fragmentation of the monoterpenes and some of their primary carbonyl oxidation products via reactions with $\mathrm{H}_{3} \mathrm{O}^{+}, \mathrm{O}_{2}^{+}$and $\mathrm{NO}^{+}$in the PTR-MS drift tube. The PTR-MS and GC-FID toluene measurements were in good quantitative agreement and the two systems tracked one another well from the instrumental limits of detection to maximum mixing ratios of $\sim 0.5 \mathrm{ppbv}$. A correlation plot of the PTR-MS versus GC-FID toluene measurements was described by the least squares regression equation $y=(1.13 \pm 0.02) x-(0.008 \pm 0.003)$ ppbv, suggesting a small $\sim 13 \%$ positive bias in the PTR-MS measurements. The bias corresponded with a $\sim 0.055 \mathrm{ppbv}$ difference at the highest measured toluene level. The two systems agreed
\end{abstract}

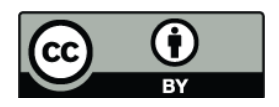

Correspondence to: J. L. Ambrose (jambrose@alumni.unh.edu) quantitatively within the combined $1 \sigma$ measurement precisions for $60 \%$ of the measurements. Discrepancies in the measured mixing ratios were not well correlated with enhancements in the monoterpenes. Better quantitative agreement between the two systems was obtained by correcting the PTR-MS measurements for contributions from monoterpene fragmentation in the PTR-MS drift tube; however, the improvement was minor $(<10 \%)$. Interferences in the PTRMS measurements from fragmentation of the monoterpene oxidation products pinonaldehyde, caronaldehyde and $\alpha$ pinene oxide were also likely negligible. A relatively large and variable toluene background in the PTR-MS instrument likely drove the measurement bias; however, the precise contribution was difficult to accurately quantify and thus was not corrected for in this analysis. The results from THF suggest that toluene can be reliably quantified by PTR-MS using our operating conditions (drift tube pressure, temperature and voltage of $2.0 \mathrm{mbar}, 45^{\circ} \mathrm{C}$ and $600 \mathrm{~V}$, respectively) under the ambient compositions probed. This work extends the range of field conditions under which PTR-MS validation studies have been conducted.

\section{Introduction}

Proton transfer reaction-mass spectrometry (PTR-MS) was recently developed for on-line monitoring of atmospheric volatile organic compounds (VOCs) (Hansel et al., 1995; Lindinger et al., 1998a). The method and its applications in atmospheric sciences were described in great detail in recent reviews (Hewitt et al., 2003; de Gouw and Warneke, 2007; Blake et al., 2009). The principal advantages of PTR-

Published by Copernicus Publications on behalf of the European Geosciences Union. 
MS are its capabilities for sensitive, high frequency measurements in real time. A disadvantage is that the method does not distinguish between isomeric/isobaric compounds; furthermore, ion fragmentation, clustering and secondary ionmolecule reactions in the drift tube can interfere in the measurement of some compounds under certain conditions (de Gouw and Warneke, 2007). Considerable effort has been made to characterize the performance of PTR-MS for quantification of atmospheric VOCs, demonstrating it to be a valuable analytical method for that purpose (Warneke et al., 2001, 2003; de Gouw et al., 2003a, b; de Gouw and Warneke, 2007). Still, the compositional diversity of the atmosphere and widespread deployment of PTR-MS for trace gas monitoring requires continued validation work be carried out, and atmospheric environments remain for which PTR-MS validation studies are lacking (de Gouw and Warneke, 2007). In particular, validation work has not been carried out in forested environments where the VOC spectrum is expected to be dominated by biogenic compounds. The present work is aimed toward the validation of PTR-MS toluene measurements based on ambient trace gas measurements at a forested site in New England.

Toluene is a ubiquitous component of atmospheric volatile organic compound loading. Atmospheric toluene measurements have been used to probe several important issues in atmospheric sciences including photochemical aging of pollutants (Roberts et al., 1984; Parrish et al., 2007; Warneke et al., 2007) and emissions inventory testing (Warneke et al., 2007; Karl et al., 2009). Additionally, several studies demonstrated that toluene may contribute to secondary organic aerosol formation in certain environments (e.g., Hurley et al., 2001).

Toluene is a significant component of fossil fuel and biomass combustion emissions (Andreae and Merlet, 2001; Schauer et al., 2002). It is also released to the atmosphere via fossil fuel and industrial solvents evaporation (Singh and Zimmerman, 1992; White et al., 2009). Although biogenic toluene emissions have not been widely observed (Helmig et al., 1998), a recent report demonstrated that toluene may be directly emitted from some plant species (White et al., 2009), as was suggested by observations from two previous studies (Heiden et al., 1999; Holzinger et al., 2000).

In the analysis of VOCs in ambient air by PTR-MS, toluene is quantified from its protonated molecular ion $\left(\mathrm{C}_{7} \mathrm{H}_{9}^{+}\right)$with a mass to charge ratio $(\mathrm{m} / \mathrm{z})$ of 93 . Previous field studies conducted under conditions dominated by anthropogenic emissions generally showed good quantitative agreement between toluene measurements made both by PTR-MS and GC techniques (Warneke et al., 2001, 2003; de Gouw et al., 2003a; Kuster et al., 2004; Rogers et al., 2006). An analysis of toluene measurements made by PTRMS and GC-MS in the New England coastal marine boundary layer, downwind of monoterpene source regions, found no evidence for interference of monoterpenes in the PTR-MS toluene measurements (de Gouw et al., 2003a).
However, laboratory investigations pertinent to PTR-MS measurements of monoterpenes $\left(\mathrm{C}_{10} \mathrm{H}_{16}\right)$, which have primarily biogenic sources (Geron et al., 2000), demonstrated that samples of several common monoterpenes and their oxidation products may, under certain conditions, yield $m / z=93$ ion fragments via reactions with $\mathrm{H}_{3} \mathrm{O}^{+}, \mathrm{O}_{2}^{+}$and $\mathrm{NO}^{+}$in the PTR-MS drift tube (Schoon et al., 2003, 2004; Tani et al., 2003, 2004; Warneke et al., 2003; Lee et al., 2006a, b; Maleknia et al., 2007). Stronger correlations between monoterpenes and the PTR-MS $m / z=93$ signal were observed in a laboratory investigation of VOC emissions from Mediterranean holm oak (Holzinger et al., 2000) and in a boreal forest environment (Rinne et al., 2005), although their origins could not be identified unambiguously. It was shown that the $m / z=93$ signal measured from holm oak could be attributed to $p$-cymene $\left(\mathrm{C}_{10} \mathrm{H}_{14}\right)$, a biogenic VOC related to the monoterpenes (Tani et al., 2003). To date, no analysis of field data has been dedicated to quantification of potential interferences in PTR-MS toluene measurements related to sampling of monoterpenes.

The present investigation used ambient measurements made at a forested site in New England under conditions of enhanced monoterpene loading to quantify potential interferences in PTR-MS toluene measurements associated with sampling of monoterpenes and their oxidation products. Details of the measurement site, the analytical systems used and the data analysis methods are given in Sect. 2. Measurements of monoterpenes by GC-FID and toluene by GCFID and PTR-MS are presented in Sect. 3, together with a quantitative analysis of potential interferences in the PTRMS toluene measurements. The major findings are summarized in Sect. 4.

\section{Methods}

\subsection{Experimental}

Measurements reported in this work were made in Durham, $\mathrm{NH}$ at the University of New Hampshire AIRMAP atmospheric monitoring network site Thompson Farm (THF) (Talbot et al., 2005) between 24 July and 15 August 2004, during the International Consortium for Atmospheric Research on Transport and Transformation (ICARTT) field campaign. The THF site $\left(43.11^{\circ} \mathrm{N}, 70.95^{\circ} \mathrm{W}, 24 \mathrm{~m}\right.$ elevation above sea level) is $24 \mathrm{~km}$ from the Gulf of Maine on an active corn farm, seasonally planted with alfalfa; it is surrounded by mixed hardwood/pine forest (Ollinger et al., 1998; Justice et al., 2002). Ambient air was drawn at $\sim 1500$ standard liters per minute through a PFA Teflon-lined aluminum manifold from the top of a $15 \mathrm{~m}$ tower using a Gast R5-Series regenerative blower (Gast Manufacturing, Inc., Benton Harbor, MI). Sub-samples were directed to a suite of trace gas analyzers housed at the base of the tower. 
Table 1. Operational and quality parameters for analytical systems operated at THF during summer 2004 and from which measurements were used in this work.

\begin{tabular}{|c|c|c|c|c|c|c|}
\hline Variables measured & Analytical Scheme & Sample cycle period & Integration time & LOD or range & Precision & Accuracy \\
\hline \multicolumn{7}{|c|}{ Chemical variables } \\
\hline Toluene & GC-FID & $\sim 40 \mathrm{~min}$ & $\sim 6 \min$ & $0.005 \mathrm{ppbv}$ & $\pm 5 \%$ & $\pm 5 \%$ a \\
\hline Monoterpenes ${ }^{b}$ & & & & $0.010 \mathrm{ppbv}$ & $\pm 5 \%$ & $\pm 5 \%$ a \\
\hline Toluene & PTR-MS & $\sim 8 \min$ & $20 \mathrm{~s}$ & $0.015 \mathrm{ppbv}$ & $\pm 5 \%$ c & $\pm 15 \% \mathrm{~d}$ \\
\hline $\mathrm{O}_{3}$ & UV absorbance $e^{\mathrm{e}}$ & $1 \mathrm{~min}$ & $1 \mathrm{~min}$ & $1 \mathrm{ppbv}$ & $\pm 1 \%$ & \\
\hline $\mathrm{NO}$ & $\mathrm{O}_{3}$ chemiluminescence & $1 \mathrm{~min}$ & $1 \mathrm{~min}$ & $0.060 \mathrm{ppbv}$ & $< \pm 17 \%$ & \\
\hline \multicolumn{7}{|c|}{ Meteorological variables } \\
\hline Pressure & Manometer & $1 \mathrm{~min}$ & $1 \mathrm{~min}$ & 500 to $1100 \mathrm{mbar}$ & $\pm 0.03 \mathrm{mbar}$ & $\pm 0.08 \mathrm{mbar}$ \\
\hline Temperature & Thermistor & $1 \mathrm{~min}$ & $1 \mathrm{~min}$ & -40 to $60^{\circ} \mathrm{C}$ & $\pm 0.1^{\circ} \mathrm{C}$ & $\pm 0.2^{\circ} \mathrm{C}$ \\
\hline Relative Humidity & Thin film capacitor & $1 \mathrm{~min}$ & $1 \mathrm{~min}$ & 0 to $100 \%$ & $\pm 0.3 \%$ & \pm 2 to $\pm 3 \%$ \\
\hline Wind speed & Anemometer & $1 \mathrm{~min}$ & $1 \mathrm{~min}$ & 0 to $75 \mathrm{~m} \mathrm{~s}^{-1 f}$ & & $\pm 1 \%$ or $\pm 0.07 \mathrm{~m} \mathrm{~s}^{-1}$ \\
\hline \multicolumn{7}{|c|}{ Other } \\
\hline$J\left(\mathrm{NO}_{2}\right)$ & Filter radiometer & $1 \mathrm{~min}$ & $1 \mathrm{~min}$ & $1 \times 10^{-6} \mathrm{~s}^{-1}$ & & \\
\hline
\end{tabular}

${ }^{\mathrm{a}}$ For standard mixing ratio. ${ }^{\mathrm{b}}$ Quality parameters derived from analysis of $n$-decane standard. ${ }^{\mathrm{c}}$ For calibration factor $\left(C_{\text {Tol }}\right)$ determination; measurement precision was estimated from counting statistics as described previously (Hayward et al., 2002; de Gouw et al., 2003a) and was $\geq 10 \%$. ${ }^{\mathrm{d}}$ Based on least squares linear regression against GC-FID toluene measurements. ${ }^{\mathrm{e}} 254 \mathrm{~nm} .{ }^{\mathrm{f}} \mathrm{Threshold}^{2}=0.45 \mathrm{~m} \mathrm{~s}{ }^{-1}$.

This work focuses on toluene measurements made using a GC system and a PTR-MS and monoterpene measurements made using the GC system. Ancillary measurements included nitric oxide (NO) by chemiluminescence (model 42CTL, Thermo Environmental Instruments, Inc, Franklin, MA), ozone $\left(\mathrm{O}_{3}\right)$ by UV photometer (model $49 \mathrm{C}-$ PS, Thermo Environmental), nitrogen dioxide photolysis frequency $\left(J\left(\mathrm{NO}_{2}\right)\right)$ by filter radiometer (Metcon, Inc., Boulder, $\mathrm{CO}$ ), and meteorological parameters, measured by a suite of Qualimetrics sensors (Qualimetrics, Inc., now All Weather, Inc., Sacramento, CA), including temperature by thermistor (model 5190C), pressure by capacitance manometer (model 7190), relative humidity (RH) by thin film capacitor (model 5190C), and wind speed by anemometer (model 2031). Selected operational parameters for each of the above measurement systems are given in Table 1. The GC system (Zhou et al., 2005) and the operational parameters of the PTR-MS were described in previous publications (Talbot et al., 2005; Ambrose et al., 2007). Specific details pertaining to the measurements in this work are described here.

The GC sample acquisition/injection system was a modified, liquid $\mathrm{N}_{2}$ cooled, Entech sample concentrator (Entech Instruments, Inc., Simi Valley, CA). Samples $\left(1200 \mathrm{~cm}^{3}\right)$ were drawn at $\sim 200 \mathrm{~cm}^{3} \mathrm{~min}^{-1}$ via a downstream pump and mass flow controller (Unit Instruments, Inc., Yorba Linda, CA) through two $20 \mathrm{~cm} \times 0.3175 \mathrm{~cm}$ Silonite-coated stainless steel loops (Entech). The first loop was cooled to $-20^{\circ} \mathrm{C}$ for sample dehumidification; the second loop was packed with 60/80 mesh glass beads (Ohio Valley Specialty Company, Marietta, $\mathrm{OH}$ ) and cooled to $-185^{\circ} \mathrm{C}$ for analyte enrichment. After sample trapping, the loops were flushed with $100 \mathrm{~cm}^{3}$ of ultra high purity (UHP) He (Maine Oxy, Auburn, Maine) at $100 \mathrm{~cm}^{3} \mathrm{~min}^{-1}$ to reduce $\mathrm{O}_{3}$-alkene reactions during heating (Sive et al., 2005). Numerous experiments have been conducted in our laboratory, as well as others (E. Apel, NCAR and D. Riemer, University of Miami, personal communication, 2003), which demonstrate that this is a reliable way to quench $\mathrm{O}_{3}$-alkene reactions for this type of system. To ensure there were no trace contaminants in the UHP $\mathrm{He}$ flow stream, it was first passed through a $1 / 4$ in $(6.35 \mathrm{~mm})$ $\times 20 \mathrm{ft}(6.10 \mathrm{~m})$ activated charcoal/molecular sieve (13X) trap $(60 / 80$ mesh) and then through a Valco heated getter helium purifier (model HP2, Valco Instruments Company, Inc., Houston, TX). The sample enrichment loop was resistively heated to $100^{\circ} \mathrm{C}$ in $\sim 10 \mathrm{~s}$ and the sample was injected in UHP He carrier (Maine Oxy, Auburn, ME), via an 8-port switching valve (SV) (Valco), into a Shimadzu 17A GC (Shimadzu Corporation, Columbia, MD), where the sample was split to four separate capillary columns. Nonmethane hydrocarbons (NMHCs) $\left(\mathrm{C}_{6}-\mathrm{C}_{11}\right)$ were separated on a $60 \mathrm{~m} \times 0.32 \mathrm{~mm}$ I.D., $1.0 \mu \mathrm{m}$ film thickness VF-5ms column (Varian, Inc., Walnut Creek, CA) and measured with a flame ionization detector (FID). Following injection, the sample dehumidification and enrichment loops were both 
heated and back-flushed with UHP He for $5 \mathrm{~min}$ at $100^{\circ} \mathrm{C}$ to clean the loops in preparation for the next sample. The sample cycle time was $\sim 42$ min with a $\sim 6$ min acquisition time. A $1200 \mathrm{~cm}^{3}$ aliquot of one of two different whole air standards was analyzed every tenth sample for quantification of target compounds and to monitor system performance. The toluene mixing ratios in the whole air standards were 1.215 and $0.101 \mathrm{ppbv}( \pm 5 \%)$. The precisions of the standard peak area measurements were $\pm 4 \%$ and $\pm 5 \%$, respectively. In this work the average $n$-decane response factor (RF), $(14.2 \pm 0.9) \times 10^{3} \mathrm{ppbv}^{-1}(1 \sigma ; n=40)$, measured from assays of the $1.215 \mathrm{ppbv}$ whole air standard was used for quantification of monoterpenes in ambient samples:

$\mathrm{RF}_{\text {decane }}=\frac{A_{\text {decane }}}{\mathrm{MR}_{\text {decane }}}$.

In Eq. (1) $A_{\text {decane }}$ is the decane chromatographic peak area determined from analysis of the whole air standard containing a known decane mixing ratio, $\mathrm{MR}_{\text {decane. Although sev- }}$ eral of the measured monoterpenes were contained in one of the whole air standards their mixing ratios were observed to decrease over time. The monoterpenes are highly reactive and were previously shown to exhibit loss in gas standards (Sive, 1998). In the course of calibration experiments with the THF GC system, various classes of hydrocarbons within each carbon number grouping were analyzed and all yielded the same per-carbon response (Table S1). For example, the toluene per-carbon response was the same as for $n$-heptane and other $\mathrm{C}_{7}$ compounds and the individual monoterpene per-carbon response was also the same as for $n$-decane (Tables S1, S2). This validated the use of a single response factor for each group of compounds (e.g., $\left.\mathrm{C}_{10}\right)$, independent of the type of NMHC (e.g., linear alkane, cyclic alkene). Furthermore, two of the gravimetric high-pressure synthetic blends from Apel-Reimer Environmental, Inc. used for the PTR-MS calibrations (see below) were quantitatively assayed and compared with the whole air standards used for the THF GC system (Table S2). The high-pressure synthetic standards were diluted to atmospheric mixing ratios (ppbv to pptv levels) with catalytic converter-prepared zero air adjusted to maintain the humidity of the sampled air. The response factors measured for the whole air and synthetic standards agreed quantitatively. (Please see Russo et al., 2010 for additional discussion of our routine GC system calibration procedures and results.)

The PTR-MS (Ionicon Analytik GmbH, Innsbruck, Austria) was operated with a drift tube pressure and temperature of $2.0 \mathrm{mbar}$ and $45^{\circ} \mathrm{C}$, respectively, and a potential of $600 \mathrm{~V}$ applied over the length $(9.6 \mathrm{~cm})$ of the drift tube. A series of 30 masses was monitored continuously; six masses were monitored for diagnostic purposes while the remaining 24 masses corresponded to the VOCs of interest (Table S3). The dwell time for each of the 24 masses was $20 \mathrm{~s}$, yielding a total measurement cycle of $\sim 8 \mathrm{~min}$. The system was zeroed every $2.5 \mathrm{~h}$ for 4 cycles by diverting the flow of ambient air through a heated catalytic converter $\left(0.5 \% \mathrm{Pd}\right.$ on alumina at $\left.450{ }^{\circ} \mathrm{C}\right)$ to oxidize the VOCs and determine system background signals. Calibrations for the PTR-MS system were conducted using three different high-pressure cylinders containing synthetic blends of selected NMHCs and oxygenated volatile organic compounds (OVOCs) at the ppbv level (Apel-Reimer Environmental, Inc., Broomfield, CO). Each of the cylinders used in the calibrations had an absolute accuracy of $< \pm 5 \%$ for all gases. Using methods similar to those described previously (Apel et al., 1998, 2003), standards were diluted to atmospheric mixing ratios (ppbv to pptv levels) with catalytic converter-prepared zero air adjusted to maintain the humidity of the sampled air. Calibrations were conducted periodically to monitor PTR-MS performance and quantify the mixing ratios of target gases. Mixing ratios for each gas were calculated by using the normalized counts per second which were obtained by subtracting out the non-zero background signal for each compound. The PTR-MS precision was estimated from counting statistics as described by Hayward et al. (2002) and de Gouw et al. (2003a). For the measurements presented below the normalized sensitivity to toluene was $15.8 \mathrm{ncps} \mathrm{ppv}^{-1}$. The background ion current for $m / z=93$, which was relatively large and variable during the ICARTT campaign period, ranged from 1.2 to $4.1 \mathrm{cps}$, with an average value of $2.3 \pm 0.6 \mathrm{cps}$. The average value of the $\mathrm{H}_{3} \mathrm{O}^{+}$ ion current was $(2.8 \pm 0.2) \times 10^{6} \mathrm{cps}$, as calculated from the measured $\mathrm{H}_{3}^{18} \mathrm{O}^{+}(\mathrm{m} / \mathrm{z}=21)$ ion current and tabulated isotopic abundances (de Bievre and Taylor, 1993). The ratio of the $\mathrm{H}_{3} \mathrm{O}^{+}\left(\mathrm{H}_{2} \mathrm{O}\right)$ ion current to that of $\mathrm{H}_{3} \mathrm{O}^{+}$was on average $10 \pm 2 \%$ and ranged from $6-15 \%$.

\subsection{Calculations}

The PTR-MS and GC-FID measurements were merged to the GC system time stamp. Only samples for which the GCFID sample trapping interval and the PTR-MS sample cycle overlapped were included. The merged data were used to estimate the potential contribution of monoterpene fragmentation in the PTR-MS drift tube to the PTR-MS signal at $m / z=93$ (nominally toluene).

The reaction of toluene (Tol) with $\mathrm{H}_{3} \mathrm{O}^{+}$in the PTR-MS drift tube to produce the protonated molecular ion, $(\mathrm{Tol}+\mathrm{H})^{+}$, at $m / z=93(m 93)$ is described by Reaction (R1),

$\mathrm{Tol}+\mathrm{H}_{3} \mathrm{O}^{+} \stackrel{k_{\mathrm{Tol}+\mathrm{H}_{3} \mathrm{O}^{+}}^{\longrightarrow}}{\longrightarrow} m 93+\mathrm{H}_{2} \mathrm{O}$,

where $k_{\mathrm{Tol}+\mathrm{H}_{3} \mathrm{O}^{+}}$is the rate constant for the reaction. Similarly, the reaction of compound $j$ with $\mathrm{H}_{3} \mathrm{O}^{+}$can be written as in Reaction (R2):

$j+\mathrm{H}_{3} \mathrm{O}^{+} \stackrel{k_{j+\mathrm{H}_{3} \mathrm{O}^{+}}}{\longrightarrow}(j+\mathrm{H})^{+}+\mathrm{H}_{2} \mathrm{O}$.

For some atmospheric VOCs, including monoterpenes, the protonated molecular ion formed via Reaction (R2) will fragment to lower $m / z$ product ions under certain PTR-MS operating conditions. The production of $m / z=93$ fragment ions 
from reaction of compound $j$ with $\mathrm{H}_{3} \mathrm{O}^{+}$can be written as in Reaction (R3),

$j+\mathrm{H}_{3} \mathrm{O}^{+} \stackrel{\phi(93)_{j} \cdot k_{j+\mathrm{H}_{3} \mathrm{O}^{+}}^{\longrightarrow}}{\longrightarrow} m 93$

where $\phi(93)_{j}$ is the $m 93$ yield resulting from ionization of compound $j$. Therefore, the total rate of change of the concentration of $m / z=93$ ions in the PTR-MS drift tube directly resulting from reaction of $\mathrm{H}_{3} \mathrm{O}^{+}$with toluene and fragmentation of other compounds $j$ is given by Eq. (2):

$\frac{d[m 93]}{d t}=k_{\mathrm{Tol}+\mathrm{H}_{3} \mathrm{O}^{+}} \cdot[\mathrm{Tol}] \cdot\left[\mathrm{H}_{3} \mathrm{O}^{+}\right]$
$+\sum_{j} k_{j+\mathrm{H}_{3} \mathrm{O}^{+}} \cdot \phi(93)_{j} \cdot[j] \cdot\left[\mathrm{H}_{3} \mathrm{O}^{+}\right]$.

The rate constant for reaction of compound $j$ with $\mathrm{H}_{3} \mathrm{O}^{+}$ and the concentration of $j$ can be expressed as fractions of the corresponding rate constant for toluene and the toluene concentration, respectively:

$k_{j+\mathrm{H}_{3} \mathrm{O}^{+}}=f_{k_{j}} \cdot k_{\mathrm{Tol}+\mathrm{H}_{3} \mathrm{O}^{+}}$,

$[j]=f_{j} \cdot[\mathrm{Tol}]$

Combining Eqs. (3) and (4) with Eq. (2) gives Eq. (5):

$$
\begin{aligned}
& \frac{d[m 93]}{d t}=k_{\mathrm{Tol}+\mathrm{H}_{3} \mathrm{O}^{+}} \cdot[\mathrm{Tol}] \cdot\left[\mathrm{H}_{3} \mathrm{O}^{+}\right] \\
& \cdot\left\{1+\sum_{j} \phi(93)_{j} \cdot f_{k_{j}} \cdot f_{j}\right\}=k_{\mathrm{Tol}+\mathrm{H}_{3} \mathrm{O}^{+} \cdot[\mathrm{Tol}]} \\
& \cdot\left[\mathrm{H}_{3} \mathrm{O}^{+}\right] \cdot\{1+F\}
\end{aligned}
$$

Integration of Eq. (5) over the time interval required for ions to traverse the drift tube, $\Delta t$, gives Eq. (6):

$[m 93]=k_{\mathrm{Tol}+\mathrm{H}_{3} \mathrm{O}^{+}} \cdot[\mathrm{Tol}] \cdot\left[\mathrm{H}_{3} \mathrm{O}^{+}\right] \cdot\{1+F\} \cdot \Delta t$.

If there are no other compounds present which fragment to $m / z=93$, all the values of $\phi(93)$ are zero, $F=0$, and Eq. (6) reduces to the standard expression for integrated signal in PTR-MS (Lindinger et al., 1998a). The toluene volume mixing ratio, $\operatorname{VMR}(m 93)$ (hereinafter referred to simply as the toluene mixing ratio), is quantified based on the ratio of the background-corrected ion current (counts per second, cps) at $m / z=93, I_{\mathrm{m} 93 \mathrm{c}}$, to the normalized ion current (ncps) for $\mathrm{H}_{3} \mathrm{O}^{+}$ as shown in Eq. (7),

$\operatorname{VMR}(m 93)=\frac{I_{m 93 \mathrm{r}}-I_{m 93 \mathrm{~b}}}{\left(\frac{I_{\mathrm{H}_{3} \mathrm{O}^{+}}}{10^{6}}\right) \cdot C_{\mathrm{Tol}}}=\frac{I_{m 93 \mathrm{c}}}{\left(\frac{I_{\mathrm{H}_{3} \mathrm{O}^{+}}}{10^{6}}\right) \cdot C_{\mathrm{Tol}}}$,

where $I_{\mathrm{m} 93 \mathrm{r}}$ and $I_{\mathrm{m} 93 \mathrm{~b}}$ are the raw and background $m / z=93$ ion currents, respectively, and $C_{\mathrm{Tol}}$ denotes the calibration factor (sensitivity) for toluene, typically expressed in units of ncps ppbv ${ }^{-1}$. Because the $\mathrm{H}_{3} \mathrm{O}^{+}\left(\mathrm{H}_{2} \mathrm{O}\right)$ ion current was low and did not depend on ambient $\mathrm{RH}$, we did not include a term for the water cluster ion current in Eq. (7) as may be necessary under different operating conditions (c.f., de Gouw and Warneke, 2007). In this work the calibration factor was determined from assays of standard gas cylinders as described in Sect. 2.1. Alternatively, the calibration factor can be determined from the instrument operating parameters, measured ion transmission efficiencies, $T r$, and published values of $k_{\mathrm{Tol}+\mathrm{H}_{3} \mathrm{O}^{+}}$and $\mathrm{H}_{3} \mathrm{O}^{+}$ion mobility, $\mu$, as described previously (de Gouw and Warneke, 2007). The measured $m / z=93$ ion current is related to the concentration at the end of the drift tube as shown in Eq. (8) (de Gouw and Warneke, 2007):

$\frac{I_{m 93 \mathrm{c}}}{I_{\mathrm{H}_{3} \mathrm{O}^{+}}}=\frac{[m 93]}{\left[\mathrm{H}_{3} \mathrm{O}^{+}\right]} \cdot \frac{\operatorname{Tr}_{m 93}}{\operatorname{Tr}_{\mathrm{H}_{3} \mathrm{O}^{+}}}$,

where here the expression is given in terms of the background-corrected $m / z=93$ ion current. In ambient air samples with contributions to [ $m 93$ ] from $j$ as described above the true toluene mixing ratio, $\operatorname{VMR}(m 93)_{t}$, and the apparent measured toluene mixing ratio, $\operatorname{VMR}(m 93)_{\mathrm{m}}$, can be defined as shown in Eq. (9), which follows from Eqs. (6-8):

$\operatorname{VMR}(\mathrm{m} 93)_{\mathrm{t}}=\operatorname{VMR}(\mathrm{m} 93)_{\mathrm{m}} \cdot \frac{1}{\{1+F\}}$.

As expected, Eq. (9) shows that the value of $\operatorname{VMR}(m 93)_{t}$ will always be smaller than that of $\operatorname{VMR}(m 93)_{m}$ in the presence of monoterpenes that fragment to ion products at $m / z=93$ (i.e., $F>0$ ). Similar to Eq. (9) corrections can be made for (1) production of ion products at $m / z=93$ from reactions of monoterpenes with $\mathrm{O}_{2}^{+}$and $\mathrm{NO}^{+}$in the PTR-MS drift tube and (2) fragmentation of monoterpene oxidation products. It should be noted that $\mathrm{O}_{2}^{+}$and $\mathrm{NO}^{+}$ionize by charge transfer rather than by proton transfer as for $\mathrm{H}_{3} \mathrm{O}^{+}$. To account for reactions of $\mathrm{O}_{2}^{+}$and $\mathrm{NO}^{+}$with $j$, additional terms that represent abundances of $\mathrm{O}_{2}^{+}$and $\mathrm{NO}^{+}$relative to $\mathrm{H}_{3} \mathrm{O}^{+}$in the PTR-MS drift tube are included in $F$ (Eq. 5). Values of $F$ were calculated using monoterpene measurements by GCFID (Sect. 3.1), as well as published proton and charge transfer rate constants and ion fragmentation yields (Sect. 3.3).

\section{Results and discussion}

\subsection{Monoterpene distributions}

Here we present GC-FID measurements of monoterpenes at THF during summer 2004. In the discussion that follows monoterpenes include $\mathrm{C}_{10} \mathrm{H}_{16}$ hydrocarbons as well as $p$-cymene $\left(\mathrm{C}_{10} \mathrm{H}_{14}\right)$, which is a related biogenic hydrocarbon (Geron et al., 2000). The monoterpene composition of plant species in the northeastern United States was previously shown to consist mostly of $\alpha$-pinene, $\Delta^{3}$ carene, $\beta$-pinene, $d$-limonene, sabinene, $\beta$-phellandrene, 
Table 2. Comparison between monoterpene emission fluxes calculated by Geron et al. (2000) for forestland encompassing the THF site and relative monoterpene abundances from mixing ratios measured by GC-FID at THF between 24 July and 15 August 2004.

\begin{tabular}{llll}
\hline & & \multicolumn{2}{c}{$\left.\mathrm{THF}^{\mathrm{N}} \%\right)^{\mathrm{b}}$} \\
Monoterpene & $E^{\circ}\left(\mu \mathrm{g} \mathrm{C} \mathrm{m}^{-2} \mathrm{~h}^{-1}\right)^{\mathrm{a}}$ & Daytime $^{\mathrm{c}}$ & Nighttime $^{\mathrm{d}}$ \\
\hline$\alpha$-pinene & $39.1(24.6)$ & $36 \pm 10$ & $40 \pm 12$ \\
$\beta$-pinene & $23.9(15.0)$ & $22 \pm 8$ & $25 \pm 7$ \\
$\Delta^{3}$-carene & $19.1(12.0)$ & $30 \pm 11$ & $25 \pm 12$ \\
$\beta$-myrcene & $16.4(10.3)$ & $7 \pm 4$ & $7 \pm 2$ \\
$d$-limonene & $16.0(10.1)$ & $\mathrm{NM}^{\mathrm{e}}$ & $\mathrm{NM}$ \\
sabinene & $8.2(5.2)$ & $4 \pm 3$ & $3 \pm 2$ \\
$p$-cymene & $6.2(3.9)$ & $\mathrm{NM}$ & $\mathrm{NM}$ \\
$\beta$-phellandrene & $4.8(3.0)$ & $\mathrm{NM}$ & $\mathrm{NM}$ \\
thujene & $1.9(1.2)$ & $\mathrm{NM}$ & $\mathrm{NM}$ \\
$\alpha$-terpinene & $1.5(0.9)$ & $\mathrm{NM}$ & $\mathrm{NM}$ \\
terpinolene & $0.3(0.2)$ & $\mathrm{NM}$ & $\mathrm{NM}$ \\
$\gamma$-terpinene & $0.16(0.1)$ & $\mathrm{NM}$ & $\mathrm{NM}$ \\
ocimene & $0.1(0.1)$ & $\mathrm{NM}$ & $\mathrm{NM}$ \\
\hline
\end{tabular}

${ }^{a} E^{\circ}$, emission flux (Geron et al., 2000); percentage of total shown in parentheses. ${ }^{b}$ Measured average $\pm 1 \sigma$ relative ambient mixing ratio distribution. ${ }^{\mathrm{c}} n=369 .{ }^{\mathrm{d}} n=244 .{ }^{\mathrm{e}} \mathrm{NM}$, not measured.

$p$-cymene, $\beta$-myrcene, ocimene, and terpinolene, whereas $\alpha$ - and $\beta$-pinene, camphene, $\Delta^{3}$-carene, $\beta$-myrcene, $d$ limonene, sabinene, $p$-cymene, and $\beta$-phellandrene were estimated to compose $>95 \%$ of summertime monoterpene emissions from forestland encompassing the THF site (Table 2) (Geron et al., 2000). At THF we identified and regularly measured $\alpha$ - and $\beta$-pinene, camphene, $\Delta^{3}$-carene, and $d$-limonene in ambient samples. All major chromatographic features observed in ambient chromatograms in the monoterpenes' retention time window were identified from whole air and synthetic standards.

Retention times (RTs) for additional monoterpenes not identified from qualitative and quantitative standards were estimated based on the observed correlation between measured RTs and published boiling point (b.p.) values for $\mathrm{C}_{9}-\mathrm{C}_{11}$ hydrocarbons in the primary working standard that eluted from the VF-5ms column between nonane $\left(\mathrm{C}_{9} \mathrm{H}_{20}\right.$; b.p. $\left.=150.82^{\circ} \mathrm{C}\right)$ and undecane $\left(\mathrm{C}_{11} \mathrm{H}_{24} ;\right.$ b.p. $\left.=195.9^{\circ} \mathrm{C}\right)$ (Fig. 1, Table 3). The elution order of the normal alkanes did not follow the same trend as the aromatics and monoterpenes and so the $n$-alkanes were excluded from the regression analysis. Peak identifications for $o$-xylene and $\mathrm{C}_{9}-\mathrm{C}_{11}$ hydrocarbons in the primary working standard are shown in Fig. 2. Table 3 lists b.p. values together with (1) mea-
Table 3. Measured retention times for $\mathrm{C}_{9}-\mathrm{C}_{11}$ hydrocarbons in the THF GC system primary working standard that eluted between nonane and undecane on the VF-5ms column together with predicted retention times for several additional monoterpenes.

\begin{tabular}{|c|c|c|}
\hline Compound & b.p. $\left({ }^{\circ} \mathrm{C}\right)^{\mathrm{a}}$ & $\mathrm{RT}(\min )^{\mathrm{b}}$ \\
\hline$n$-nonane & 150.82 & $10.18 \pm 0.04$ \\
\hline$i$-propylbenzene & 152.41 & $10.89 \pm 0.05$ \\
\hline$\alpha$-pinene & 156.2 & $11.14 \pm 0.04$ \\
\hline$n$-propylbenzene & 159.24 & $11.54 \pm 0.05$ \\
\hline camphene & 158 to 161 & $11.5 \pm 0.3^{\mathrm{c}}$ \\
\hline 3-ethyltoluene & 161.3 & $11.68 \pm 0.05$ \\
\hline 4-ethyltoluene & 162 & $11.76 \pm 0.05$ \\
\hline 1,3,5-TMB & 164.74 & $11.85 \pm 0.05$ \\
\hline 2-ethyltoluene & 165.2 & $12.09 \pm 0.05$ \\
\hline$\beta$-pinene & 166 & $12.17 \pm 0.05$ \\
\hline$n$-decane & 174.15 & $12.27 \pm 0.05$ \\
\hline$\beta$-myrcene & 167 & $12.2 \pm 0.2^{\mathrm{c}}$ \\
\hline $1,2,4-\mathrm{TMB}$ & 169.38 & $12.43 \pm 0.05$ \\
\hline$\Delta^{3}$-carene & 171 & $12.6 \pm 0.2^{\mathrm{c}}$ \\
\hline$\beta$-phellandrene & 171.5 & $12.6 \pm 0.1$ \\
\hline 1,2,3-TMB & 176.12 & $13.08 \pm 0.05$ \\
\hline$\alpha$-terpinene & 174 & $12.9 \pm 0.2^{\mathrm{c}}$ \\
\hline ocimene & 177 & $13.1 \pm 0.2^{\mathrm{d}}$ \\
\hline$p$-cymene & 177.1 & $13.2 \pm 0.1^{\mathrm{c}}$ \\
\hline$d$-limonene & 178 & $13.18 \pm 0.05$ \\
\hline 1,3-DEB & 181.1 & $13.54 \pm 0.05$ \\
\hline 1,4-DEB & 183.7 & $13.75 \pm 0.05$ \\
\hline 1,2-DEB & 184 & $13.84 \pm 0.06$ \\
\hline$\gamma$-terpinene & 183 & $13.7 \pm 0.2^{\mathrm{c}}$ \\
\hline terpinolene & 186 & $14.0 \pm 0.2^{\mathrm{c}}$ \\
\hline undecane & 195.9 & $14.42 \pm 0.06$ \\
\hline
\end{tabular}

${ }^{\mathrm{a}}$ (Lide, 2008). ${ }^{\mathrm{b}}$ Measured average $\pm 3 \sigma$ except where noted otherwise. ${ }^{c}$ Derived from linear regression between RT and b.p. for compounds in the primary working standard; errors represent $0.01-$ $1{ }^{\circ} \mathrm{C}$ uncertainty in b.p. values and the $95 \%$ prediction interval on the RT values determined from regression analysis. d (Graedel, 1979). Abbreviations: TMB, trimethylbenzene; DEB, diethlylbenzene.

sured average RTs for $\mathrm{C}_{9}-\mathrm{C}_{11}$ hydrocarbons identified in Fig. 2 and (2) RTs predicted based on the regression analysis shown in Fig. 1 for several additional monoterpenes. 
For comparison, the regression analysis shown in Fig. 1 predicted RTs for camphene and $\Delta^{3}$-carene of $11.5 \pm 0.3 \mathrm{~min}$ and $12.6 \pm 0.2 \mathrm{~min}$ (Table 3), whereas the values measured from a multi-component synthetic standard were $\sim 11.6 \mathrm{~min}$ and $\sim 12.8 \mathrm{~min}$, respectively. The agreement between predicted and measured RTs indicated that the RT versus b.p. relationship determined for $\mathrm{C}_{9}-\mathrm{C}_{11}$ hydrocarbons in the primary working standard was a good predictor of RTs for monoterpenes when measured values were not available.

Figure 3 shows an example chromatogram from the night of 2 August, when significantly elevated monoterpene mixing ratios were measured. The unidentified peak at $\sim 13.3 \mathrm{~min}$, labeled "UnID", was within the estimated RT windows for ocimene and $p$-cymene (Table 3), which were not identified from qualitative and quantitative standards. The area of the unidentified peak was strongly correlated with those of the other major monoterpenes, as illustrated in Fig. 4; however, it typically represented a minor fraction of the total monoterpene mixing ratio. Other minor features that could be attributed to $\beta$-phellandrene, $\alpha$ terpinene, $\gamma$-terpinene, and terpinolene were also observed while the monoterpene mixing ratio was elevated; however, the corresponding mixing ratios, estimated using the $n$-decane RF, were typically below the instrumental limit of detection (LOD) for the monoterpenes $(0.010 \mathrm{ppbv})$. Due to their apparent low abundance monoterpenes other than those measured (Table 2) were not considered in the following analysis.

A time series of the monoterpene mixing ratios measured between 24 July, 22:00 LT and 15 August, 06:00 LT is presented in Fig. 5. Measurements of $J\left(\mathrm{NO}_{2}\right)$, expressed as $10 \mathrm{~min}$ average values normalized to the summertime (June to August) maximum, $7.9 \times 10^{-3} \mathrm{~s}^{-1}$, reflect relative solar irradiance intensity and delineate daytime and nighttime periods. The highest monoterpene mixing ratios were measured during the nighttime hours under calm conditions (wind speed $<0.5 \mathrm{~m} \mathrm{~s}^{-1}$ ) and with more humidity (Geron et al., 2000). Previous work demonstrated that the nocturnal boundary layer in the region encompassing the THF site can lead to nighttime surface enhancements in trace gases with local emissions sources (Talbot et al., 2005; White et al., 2008), which likely contributed significantly to the nighttime monoterpene maxima. The observed daytime minima in the monoterpene mixing ratios were likely driven by the increased height of the boundary layer as well as greater oxidation by hydroxyl radical $(\mathrm{OH})$ and $\mathrm{O}_{3}$ during the daytime despite higher monoterpene emissions during the day owing to warmer temperature (Guenther et al., 1993).

Table 2 compares summertime monoterpene fluxes estimated by Geron et al. (2000) for forestland encompassing the THF site and average relative ambient monoterpene distributions for summer 2004 based on data shown in Fig. 5. The flux estimates were derived from regional tree species distributions, monoterpene composition and emissions at $30^{\circ} \mathrm{C}$ (Geron et al., 2000). The estimated flux distribution and mea- sured mixing ratio distributions were in partial quantitative agreement for the dominant monoterpenes, except a greater abundance of camphene than $\beta$-pinene was measured, and $\beta$-myrcene was not measured. The daytime and nighttime mixing ratio distributions were in close agreement despite large diurnal differences in the absolute mixing ratios. This is consistent with boundary layer dynamics being a significant factor governing monoterpene abundances at THF as was observed previously in a different forested environment (Roberts et al., 1985).

Based on data collected between 1990 and 1999, land cover in Strafford County, where the THF site is situated, consisted mostly of mixed forestland ( $\sim 57 \%$ of forestland) and deciduous tree species ( $\sim 30 \%$ of forestland) (Justice et al., 2002). For such land cover monoterpene composition and emissions data were relatively scarce when the regional monoterpenes flux estimates shown in Table 2 were compiled (Geron et al., 2000). Thus, it is conceivable that local patterns of tree species distribution and monoterpene emissions contributed to the differences between the emissions and mixing ratio distributions in Table 2 . The monoterpenes react rapidly with $\mathrm{OH}, \mathrm{O}_{3}$ and the nitrate radical $\left(\mathrm{NO}_{3}\right)$ (Atkinson, 1994; Atkinson and Arey, 2003), and monoterpene oxidation between emission and sampling likely contributed to the measured monoterpene distribution at THF. The lifetime of $\beta$-myrcene with respect to reaction with $\mathrm{O}_{3}$ is much shorter than for the monoterpenes measured at THF (Atkinson and Arey, 2003), which might partially explain why $\beta$-myrcene was not measured in ambient air at THF, despite the relatively high $\beta$-myrcene emissions flux predicted for the THF region (Geron et al., 2000).

\subsection{GC-FID/PTR-MS toluene field comparison}

Several laboratory and field comparisons between PTR-MS and GC-based toluene measurements were conducted previously, with most studies demonstrating good quantitative agreement between PTR-MS and the more established chromatography-based measurement techniques. These include comparison of PTR-MS with (1) GC-FID (offline) at a suburban site in the Netherlands during March 2000 (Warneke et al., 2001); (2) GC-MS, with ion trap and quadrupole MS, at a suburban site in Houston, TX during August and September 2000 (Kuster et al., 2004); (3) GCMS aboard a research ship in the New England coastal marine boundary layer (CMBL) during July and August 2002 (de Gouw et al., 2003a); (4) GC-FID at a suburban site in Tokyo, Japan during November 2002 (Kato et al., 2004); (5) GC-FID (offline) at a laboratory biomass combustion facility (Christian et al., 2004); (6) GC-FID (offline) in the Mexico City metropolitan area during April and May 2003 (Rogers et al., 2006); (7) GC-FID (offline) aboard a research aircraft over New England and eastern Canada during July 2004 (de Gouw et al., 2006); and (8) GC-MS and GC-FID (offline) 
Table 4. Quantitative comparison between GC-FID and PTR-MS toluene measurements for different monoterpene fragmentation corrections applied to the PTR-MS data.

\begin{tabular}{lllll}
\hline \multicolumn{5}{c}{ Regression Parameters } \\
Treatment $^{\mathrm{a}}$ & $m^{\mathrm{b}}$ & $b^{\mathrm{b}}$ & $r^{2}$ & \% Agreement \\
\hline $\mathrm{A}$ & $1.13 \pm 0.02$ & $-0.008 \pm 0.003$ & 0.908 & 60.1 \\
$\mathrm{~A}^{\prime}$ & $1.16 \pm 0.02$ & $-0.011 \pm 0.001$ & 0.908 & 60.1 \\
$\mathrm{~B}$ & $1.07 \pm 0.02$ & $-0.005 \pm 0.002$ & 0.910 & 62.8 \\
$\mathrm{C}$ & $1.00 \pm 0.02$ & $-0.003 \pm 0.002$ & 0.907 & 64.8 \\
$\mathrm{D}$ & $0.84 \pm 0.02$ & $0.004 \pm 0.002$ & 0.858 & 57.6 \\
$\mathrm{E}$ & $1.10 \pm 0.02$ & $-0.007 \pm 0.002$ & 0.911 & 61.0 \\
$\mathrm{~F}$ & $0.97 \pm 0.02$ & $-0.002 \pm 0.002$ & 0.909 & 65.3 \\
\hline
\end{tabular}

a Data treatment description: A, PTR-MS data uncorrected, correlation analyzed using simple least squares regression; $\mathrm{A}^{\prime}$, same as A, but analyzed using orthogonal least squares regression with variance ratio, $\lambda=\sigma_{\mathrm{PTR}-\mathrm{MS}}^{2} / \sigma_{\mathrm{GC}-\mathrm{FID}}^{2}=4.6 \pm 1.6$; B, PTR-MS data corrected assuming $\phi(93)=1 \%$ for reaction of $\mathrm{H}_{3} \mathrm{O}^{+}$with $\alpha$-pinene; $\mathrm{C}$, same as $\mathrm{B}$, but $\phi(93)=2 \%$ for $\alpha$-pinene and $1 \%$ for $\beta$-pinene; $\mathrm{D}$, same as $\mathrm{B}$, but $\phi(93)=7 \%$ for $\alpha$-pinene; E, PTR-MS data corrected for reactions of $\mathrm{O}_{2}^{+}$with measured monoterpenes using $\phi(93)$ from Schoon et al. (2003); F, PTRMS data corrected for reactions of $\mathrm{H}_{3} \mathrm{O}^{+}$, as in treatment $\mathrm{C}$, and $\mathrm{O}_{2}^{+}$, as in treatment $\mathrm{E}$. ${ }^{\mathrm{b}}$ Uncertainties are standard errors, except those for orthogonal least squares parameters which reflect $1 \sigma$ range of $\lambda^{c}$ Percentage of samples for which GC-FID and PTR-MS values agreed within combined $1 \sigma$ measurement precisions.

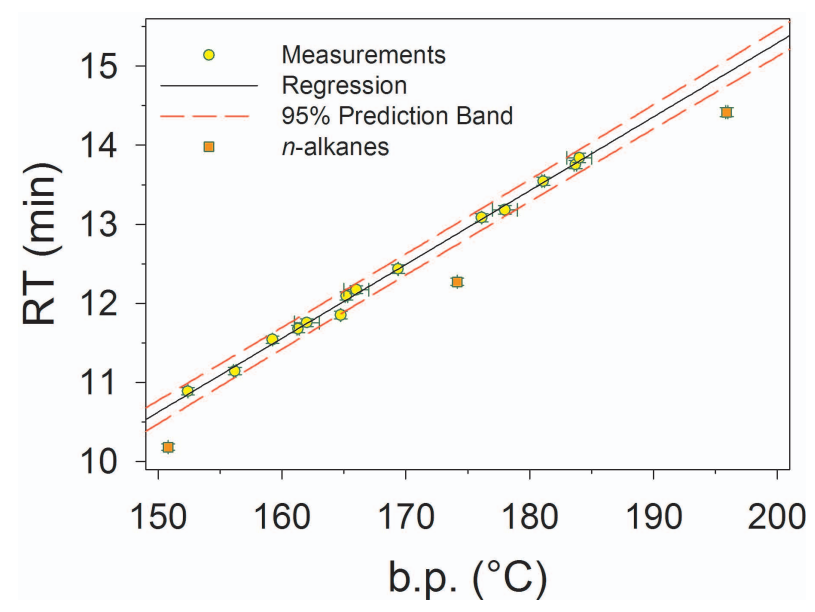

Fig. 1. Linear correlation between elution order (retention time) and boiling point for $\mathrm{C}_{9}-\mathrm{C}_{11}$ compounds in the THF GC system primary working standard that eluted from the VF-5ms column between nonane and undecane. The regression line was derived by a simple least squares analysis which excluded data for the $n$-alkanes. Error bars are 0.04-0.06 min, representing $3 \sigma$ of the mean values determined from standard chromatograms, and $0.01-1{ }^{\circ} \mathrm{C}$ (taken to be 1 unit in the least significant digit of the literature b.p. values).

aboard a research aircraft in the vicinity of Mexico City during March 2006 (Karl et al., 2009).

Analyses coupling GC with PTR-MS (GC-PTR-MS) were also employed to determine the specificity of PTR-MS for measuring atmospheric toluene. In air samples collected at urban sites (Utrecht, The Netherlands and Boulder, $\mathrm{CO}$ ) during March 2001 and January 2002 and a remote site in the Austrian Alps during March 2001 only toluene contributed to the PTR-MS $m / z=93$ signal (de Gouw et al., 2003b; Warneke et al., 2003). Laboratory GC-PTR-MS measurements showed $\alpha$ - and $\beta$-pinene to yield minor quantities of $m / z=93$ ion fragments (Warneke et al., 2003). To accommodate the laboratory results de Gouw et al. (2003a) fit PTRMS $m / z=93$ signal to a linear combination of toluene and either $\alpha$ - or $\beta$-pinene measured by GC-MS using data collected in the New England CMBL during summertime. However, they did not obtain significant contributions from $\alpha$ - and $\beta$ pinene to PTR-MS $m / z=93$ signal under conditions of elevated monoterpene mixing ratios.

Here we compare toluene measurements by GC-FID and PTR-MS from the AIRMAP THF monitoring site during the summer of 2004. Figure 6 shows time series of toluene mixing ratios measured by GC-FID and PTR-MS from 24 July, 22:00 LT to 15 August, 06:00 LT. Overall the two systems tracked each other well from values at or near the GC-FID and PTR-MS LODs (0.005 and $0.015 \mathrm{ppbv}$, respectively) to maxima of $0.42 \pm 0.02 \mathrm{ppbv}$ (GC-FID) and $0.52 \pm 0.03 \mathrm{ppbv}$ (PTR-MS).

The GC-FID and PTR-MS data sets yielded 351 merged samples in which toluene was above the LOD for the PTR$\mathrm{MS}$ and GC-FID, with median toluene mixing ratios of $0.085 \pm 0.006 \mathrm{ppbv}$ (GC-FID) and $0.085 \pm 0.017 \mathrm{ppbv}$ (PTRMS). For $60 \%$ of the merged samples the toluene mixing ratios measured with the two systems agreed quantitatively 


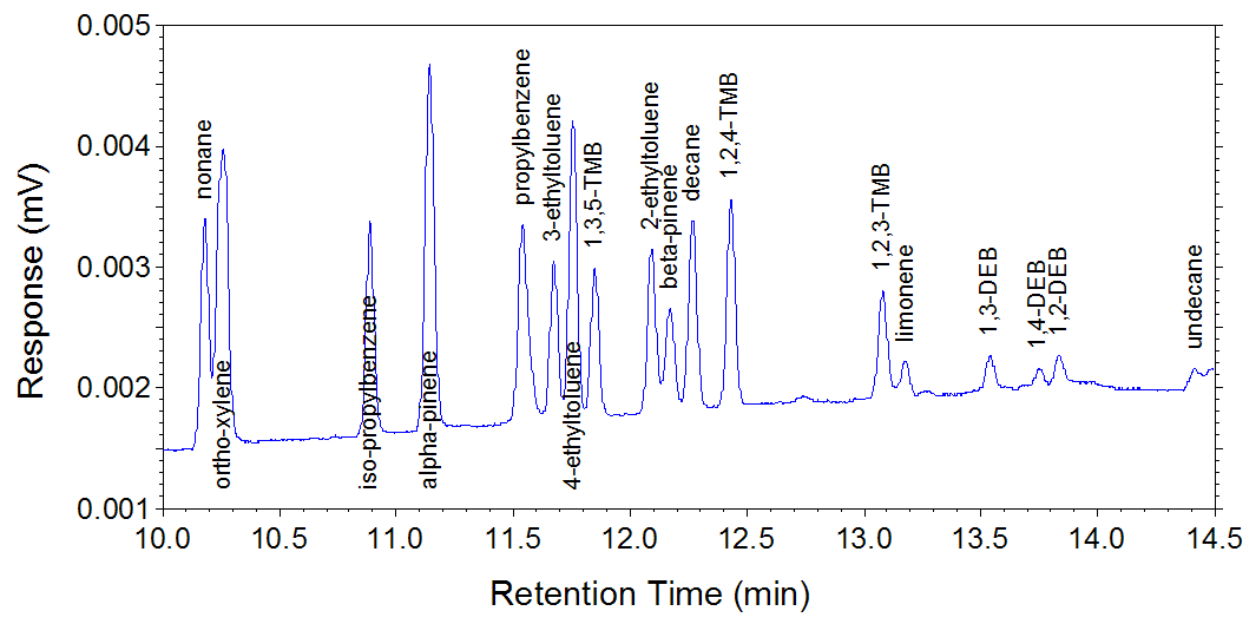

Fig. 2. Portion of a chromatogram from the THF GC system primary working standard showing identification of compounds that eluted between nonane and undecane on the VF-5ms column. The temperature program employed was $35^{\circ} \mathrm{C}$ for $2 \mathrm{~min}^{\circ} 10^{\circ} \mathrm{C}$ min ${ }^{-1}$ to $115^{\circ} \mathrm{C}$, $7^{\circ} \mathrm{C} \min ^{-1}$ to $200^{\circ} \mathrm{C}$ for $5 \mathrm{~min}$. Abbreviations: TMB, trimethylbenzene; DEB, diethylbenzene.

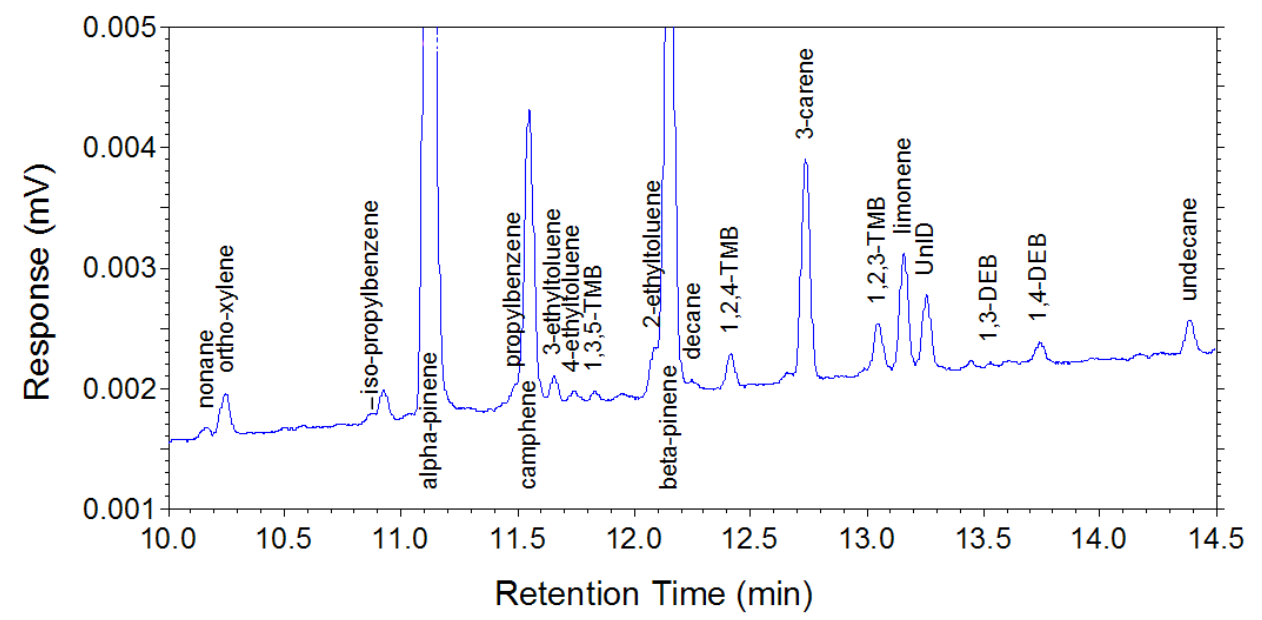

Fig. 3. Portion of a chromatogram recorded at THF on 3 August, 04:23 LT during a period of elevated monoterpene mixing ratios.

within the combined $1 \sigma$ measurement precisions. Despite a significant background subtraction applied to the PTR-MS measurements, the two systems were in good quantitative agreement. Figure 7 shows a linear correlation plot for the merged data. The parameters of simple least squares regression and orthogonal least squares regression (determined using JMP ${ }^{\mathrm{TM}}$ statistical software) are given in Table 4 (Treatments $\mathrm{A}$ and $\mathrm{A}^{\prime}$, respectively). Orthogonal least squares accounts for errors in both independent and dependent variables (Tan and Iglewicz, 1999) and was applied in previous comparisons between ambient PTR-MS and GC-MS toluene measurements (de Gouw et al., 2003a; Warneke et al., 2003). As shown in Table 4 the results of both regression analyses agree quantitatively in terms of the regression parameters and the coefficients of determination. In the following discussion the results of different treatments of the PTR-MS toluene data are analyzed in terms of simple least squares regression parameters.

\subsection{Sources of interference from monoterpene fragmentation}

The $\mathrm{C}_{10} \mathrm{H}_{16}$ monoterpenes are typically detected by PTR-MS as the protonated molecular ion $(m / z=137)$ and a dominant fragment ion with $m / z=81$. As discussed in greater detail below $m / z=93$ ions may also be generated from monoterpene fragmentation in the PTR-MS drift tube. The $m / z=93,81$ and 137 signals were observed by PTR-MS in a laboratory study of VOC emissions from Mediterranean holm oak (Holzinger et al., 2000), consistent with (1) a biogenic toluene source, as was observed from sunflower and Scots pine by GC-MS (Heiden et al., 1999) and alfalfa by GC-FID (White et al., 2009), and (2) monoterpene fragmentation in the PTR-MS 
Table 5. Comparison of reported yields of $m / z=93$ fragment ions associated with analysis of monoterpenes by PTR-MS and SIFTMS.

\begin{tabular}{|c|c|c|c|c|}
\hline \multicolumn{5}{|c|}{$\phi(93)(\%)$ vs. Reagent } \\
\hline Monoterpene & $\mathrm{H}_{3} \mathrm{O}^{+\mathrm{a}}$ & $\mathrm{O}_{2}^{+\mathrm{b}}$ & $\mathrm{NO}^{+} \mathrm{b}$ & $\phi(81)(\%)^{\mathrm{a}, \mathrm{c}}$ \\
\hline \multirow[t]{5}{*}{$\alpha$-pinene } & $12^{\mathrm{d}}$ & $52^{\mathrm{e}}$ & $4^{\mathrm{e}}$ & $57^{\mathrm{d}, \mathrm{f}}$ \\
\hline & $7^{\mathrm{g}}$ & & & $45^{\mathrm{h}, \mathrm{i}}$ \\
\hline & $1^{\mathrm{e}}$ & & & $40^{\mathrm{j}, \mathrm{k}}$ \\
\hline & $<1^{1}$ & & & $31^{\mathrm{g}, \mathrm{m}}$ \\
\hline & $<0.1^{\mathrm{j}, \mathrm{k}}$ & & & $30^{\mathrm{e}, \mathrm{b}}$ \\
\hline camphene & $<1^{\mathrm{d}, \mathrm{e}}$ & $13^{\mathrm{e}}$ & $<1^{\mathrm{e}}$ & \\
\hline \multirow[t]{4}{*}{$\beta$-pinene } & $7^{\mathrm{g}}$ & $56^{\mathrm{e}}$ & $3^{\mathrm{e}}$ & $70^{\mathrm{d}, \mathrm{f}}$ \\
\hline & $<1^{\mathrm{d}, \mathrm{e}, 1}$ & & & $40^{\mathrm{j}, \mathrm{k}}$ \\
\hline & $<0.1^{\mathrm{j}, \mathrm{k}}$ & & & $33^{\mathrm{e}, \mathrm{b}}$ \\
\hline & & & & $26^{\mathrm{g}, \mathrm{m}}$ \\
\hline \multirow[t]{2}{*}{$\beta$-myrcene } & $1^{\mathrm{e}}$ & $61^{e}$ & $22^{\mathrm{e}}$ & $26^{\mathrm{e}, \mathrm{b}}$ \\
\hline & $<1^{\mathrm{d}, \mathrm{e}, 1}$ & $1^{\mathrm{e}}$ & & \\
\hline \multirow[t]{2}{*}{$\Delta^{3}$-carene } & $<1^{\mathrm{d}, \mathrm{e}, 1}$ & $41^{\mathrm{e}}$ & $4^{\mathrm{e}}$ & $30^{\mathrm{j}, \mathrm{k}}$ \\
\hline & $<0.1^{\mathrm{j}, \mathrm{k}}$ & & & $19^{\mathrm{e}, \mathrm{b}}$ \\
\hline \multirow[t]{2}{*}{$\alpha$-terpinene } & $<20^{\mathrm{n}}$ & & & \\
\hline & $<1^{1}$ & & & \\
\hline \multirow[t]{2}{*}{$p$-cymene } & $91^{\mathrm{d}}$ & & & \\
\hline & $85^{\mathrm{h}, \mathrm{i}}$ & & & \\
\hline \multirow[t]{3}{*}{$d$-limonene } & $1^{\mathrm{d}}$ & $26^{\mathrm{e}}$ & $<1^{\mathrm{e}}$ & $72^{\mathrm{d}, \mathrm{f}}$ \\
\hline & $<1^{\mathrm{e}}$ & & & $40^{\mathrm{j}, \mathrm{k}}$ \\
\hline & $<0.1^{\mathrm{j}, \mathrm{k}}$ & & & $22^{e, b}$ \\
\hline \multirow[t]{2}{*}{$\gamma$-terpinene } & $3^{\mathrm{d}}$ & & & \\
\hline & $<1^{\mathrm{n}}$ & & & \\
\hline terpinolene & $<1^{\mathrm{d}, 1}$ & & & \\
\hline
\end{tabular}

${ }^{\mathrm{a}} \mathrm{NO}^{+}$and $\mathrm{O}_{2}^{+}$abundances were not specified and ion transmission efficiency corrections were not applied in the PTR-MS studies and may have contributed to the reported ion yields. b SIFT-MS; He carrier gas; yield corrected for ion transmission efficiency. ${ }^{\mathrm{c}}$ From reaction with $\mathrm{H}_{3} \mathrm{O}^{+}$. d (Maleknia et al., 2007). " (Schoon et al., 2003). f $E / N=140-150$ Td. g (Warneke et al., 2003). h (Tani et al., 2004). ${ }^{\mathrm{i}} E / N=142 \mathrm{Td} .{ }^{\mathrm{j}}$ (Tani et al., 2003). ${ }^{\mathrm{k}} E / N=120 \mathrm{Td}$; percentage of total ion signal including isotopic signal. ${ }^{1}$ (Lee et al., 2006a). ${ }^{\mathrm{m}} E / N=106$ Td. ${ }^{\mathrm{n}}$ (Lee et al., 2006b).
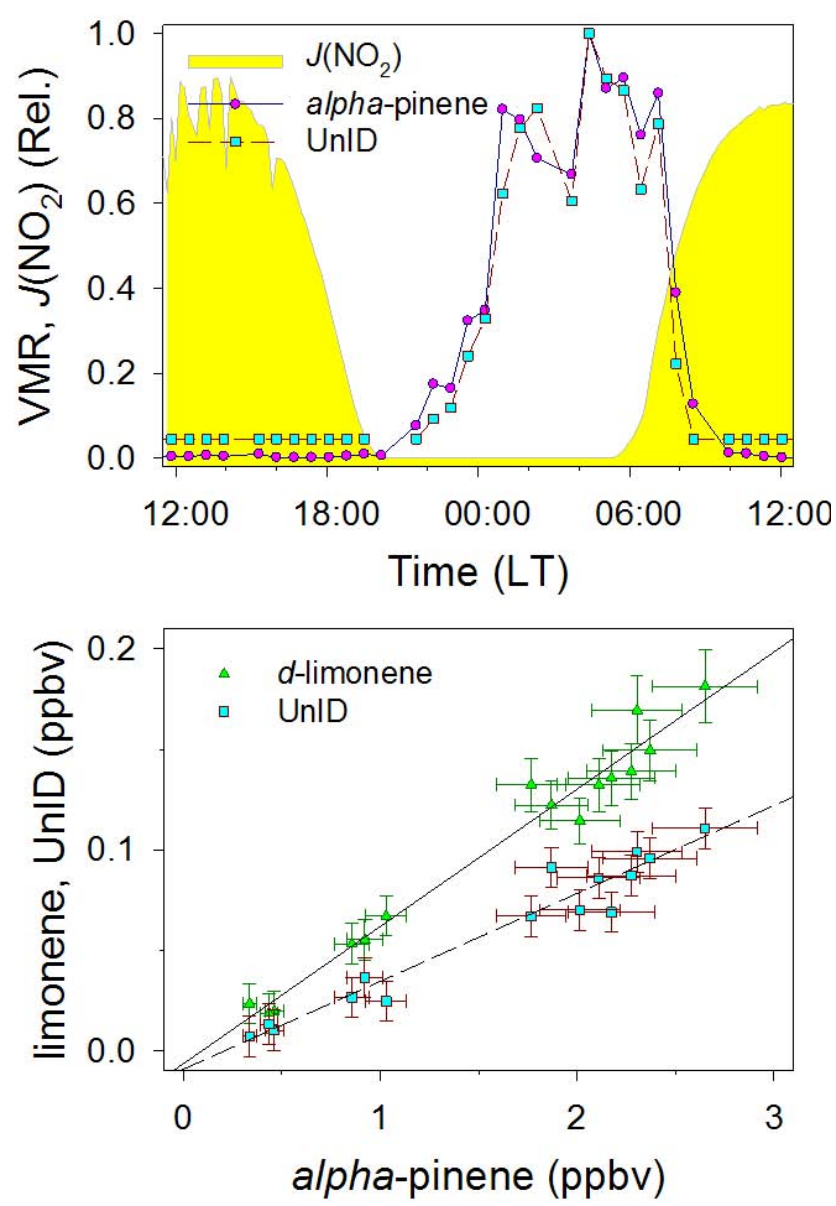

Fig. 4. Comparison of trends in the mixing ratios of $\alpha$-pinene and an unidentified (UnID) compound (assumed to be $\mathrm{C}_{10}$ ) during the period from 2 August, 12:00 LT to 3 August, 12:00 LT; (a) time series of relative mixing ratios; (b) linear regression of absolute mixing ratios. The $J\left(\mathrm{NO}_{2}\right)$ data in (a) are $10 \mathrm{~min}$ averages and delineate daytime and nighttime periods. In (b) the correlation between the $d$-limonene and $\alpha$-pinene mixing ratios is shown for comparison. The coefficients of determination $\left(r^{2}\right)$ for the regression lines were 0.97 and 0.95 for $d$-limonene and UnID, respectively. Error bars represent the greater of the measurement precision or LOD. Mixing ratios below the LOD were set to $0.5 \times \mathrm{LOD}$ in (a) and were excluded from the regression in (b).

drift tube (Tani et al., 2003). In a factor analysis applied to PTR-MS measurements of VOCs in a boreal forest during July 2004 the $m / z=93,81$ and 137 signals loaded strongly on the same factor (Rinne et al., 2005); however, the implications were not discussed.

Here we discuss several possible sources of interferences in PTR-MS analysis of toluene related to simultaneous sampling and analysis of monoterpenes. During the period from 24 July to 15 August 2004 toluene and monoterpenes were quantified by GC-FID from a total of 600 ambient samples at THF. The ratio of the monoterpene mixing ratio to the GC-FID toluene mixing ratio, hereinafter denoted by $\Delta_{\text {Mon }}$, 

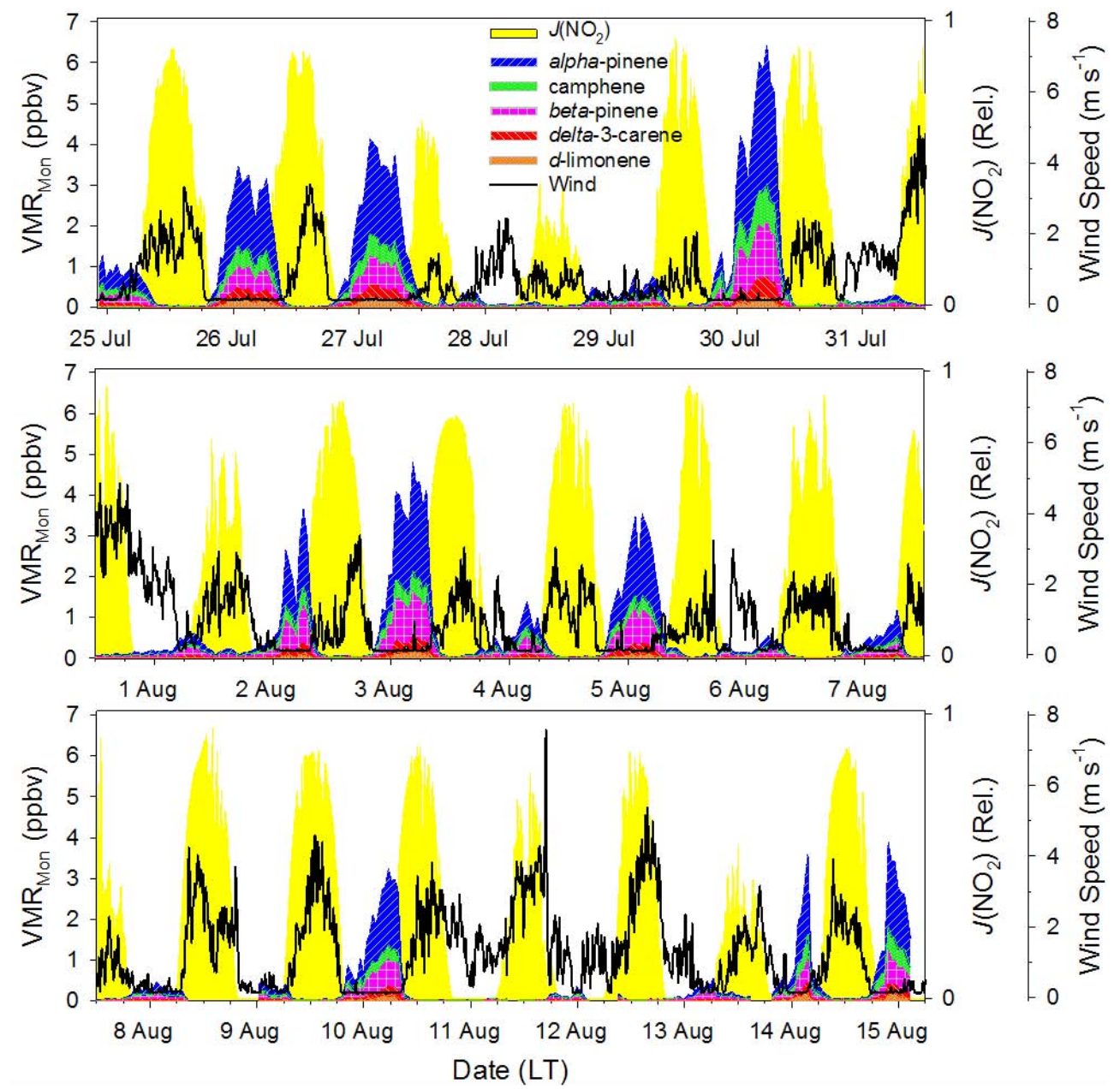

Fig. 5. Time series of monoterpenes, $J\left(\mathrm{NO}_{2}\right)$ (10 min averaged) and wind speed (10 min averaged) measured at THF from $24 \mathrm{July}, 22: 00 \mathrm{LT}$ to 15 August, 06:00 LT. Values of $J\left(\mathrm{NO}_{2}\right)$ relative to the summertime maximum delineate daytime and nighttime periods. Mixing ratios below the LOD were set to $0.5 \times$ LOD.

ranged from $<0.25$ to $31 \pm 2$, with a median value of 2.4. For the merged data set $(n=349)$ the median value of $\Delta_{\text {Mon }}$ was 2.6 \pm 0.2 . By comparison maximum $\Delta_{\text {Mon }}$ values of $>5$ were reported from measurements made in the Gulf of Maine during summer of 2002 (de Gouw et al., 2003a). Thus, it appears we observed relatively large enhancements in monoterpenes relative to toluene at the THF site during summer 2004 and our data provide a unique test of the specificity of PTR-MS for measurement of toluene in an atmospheric environment strongly influenced by biogenic monoterpene emissions.

It is expected that the generation of ion products at $m / z=93$ by monoterpene fragmentation in the PTR-MS drift tube would result in (1) a positive bias in the PTR-MS toluene measurements as compared with the GC-FID measurements, and (2) a positive correlation between $\Delta_{\text {Mon }}$ and the magnitude of the PTR-MS bias. An overall small positive bias of $\sim 13 \%$ was observed in the PTR-MS measurements as indicated by the slope of the least squares regression fit to the merged data in Fig. 7 (Table 4, treatment A). The observed bias is consistent with an additional source of $m / z=93$ ions in the PTR-MS instrument. Since the FID response factors for the PTR-MS toluene standard and the whole air standards run on the GC system agreed to within stated uncertainties, it appeared that calibration errors were not the cause of the PTR-MS bias. The PTR-MS instrument background at $m / z=93$ accounted for on average $38 \pm 16 \%$ of the total $m / z=93$ ion current and was therefore relatively high. It was on average $\sim 4$-fold larger than the $m / z=93$ ion current corresponding with the PTR-MS bias. The background $m / z=93$ ion current showed significant variability and did not correlate with the toluene mixing ratio. Excluding from our analysis times when the largest relative background $m / z=93$ ion currents were measured did not significantly reduce the PTRMS bias. Although we could not accurately quantify the contribution, it is likely that the relatively large and variable $m / z=93$ background current in the PTR-MS instrument was 

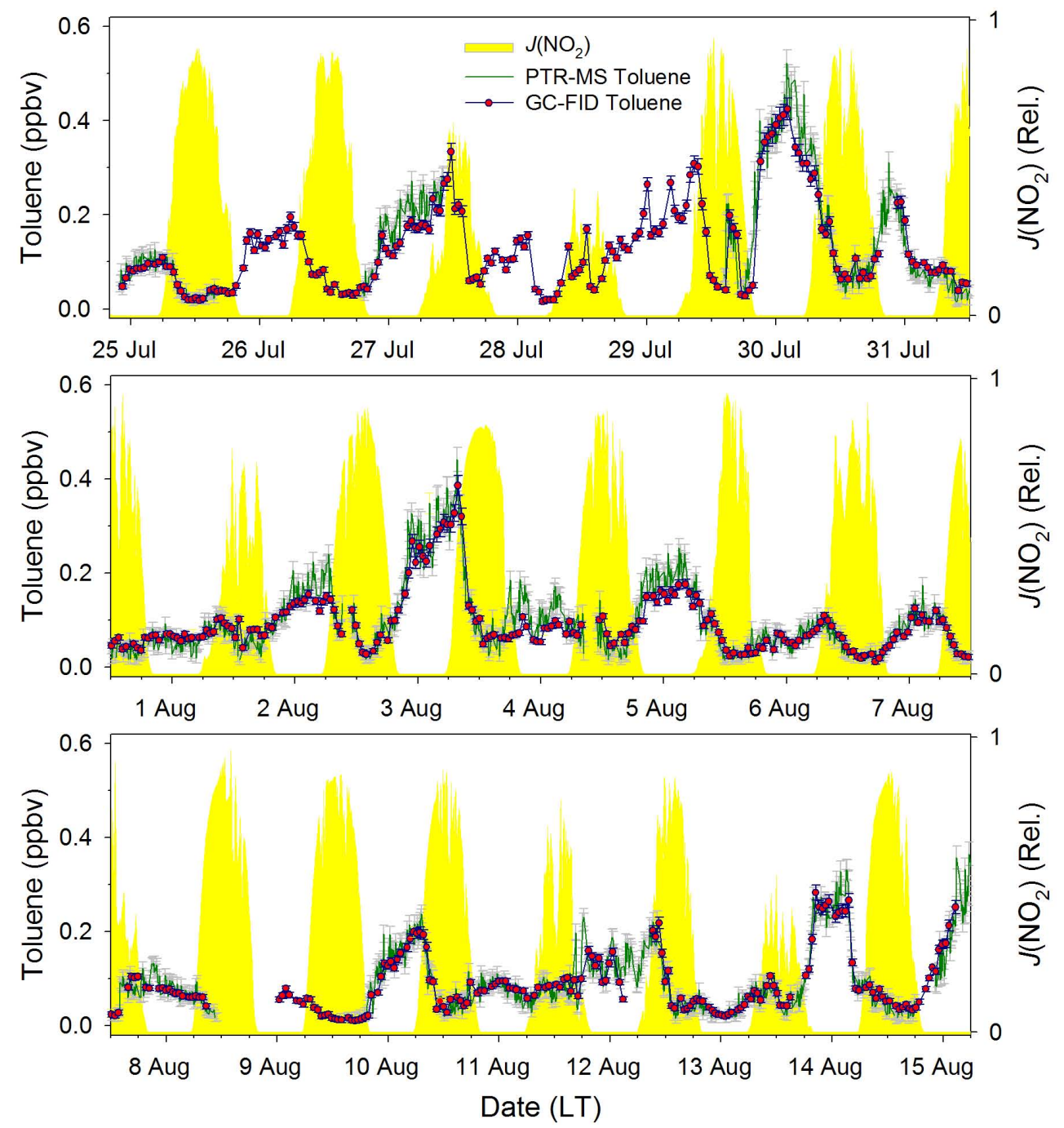

Fig. 6. Time series of toluene measured by GC-FID and PTR-MS during the period between 24 July, 22:00 LT and 15 August, 06:00 LT. Values of $J\left(\mathrm{NO}_{2}\right)$ are show as in Fig. 5. Errors in the GC-FID and PTR-MS data are the greater of the $1 \sigma$ measurement precision or LOD.

the primary driver of the measurement bias. Figure 8 compares time series of the PTR-MS error (percent difference with respect to the GC toluene measurements),hereinafter denoted as $\varepsilon$ PTR-MS, and $\Delta_{\text {Mon }}$. Maxima in the values of $\varepsilon_{\text {PTR-MS }}$ and $\Delta_{\text {Mon }}$ generally occurred during nighttime but did not appear to be well correlated, suggesting qualitatively that interference in the PTR-MS toluene measurements from monoterpene fragmentation was unimportant at THF. Quantitative estimates of potential interferences in the PTR-MS toluene measurements are presented below.

\subsubsection{Reactions with $\mathrm{H}_{3} \mathrm{O}^{+}$}

Ion products were detected at $m / z=93$ in laboratory PTRMS analyses of six monoterpenes, $\alpha$-pinene (Warneke et al., 2003; Maleknia et al., 2007), $\beta$-pinene (Warneke et al., 2003), $d$-limonene (Maleknia et al., 2007), $\gamma$-terpinene
(Maleknia et al., 2007), $\alpha$-terpinene (Lee et al., 2006b), and $p$-cymene (Tani et al., 2003, 2004; Maleknia et al., 2007), and in the analysis of $\alpha$-pinene and $\beta$-myrcene by selected ion flow tube mass spectrometry (SIFT-MS) using $\mathrm{H}_{3} \mathrm{O}^{+}$as reagent ion (Schoon et al., 2003). Table 5 compares yields of $m / z=93$ fragment ions, $\phi(93)$, reported in the literature. When more than one set of operating parameters was employed, as in several of the above studies (Tani et al., 2003, 2004; Maleknia et al., 2007), fragmentation data chosen for comparison in Table 5 correspond with operating parameters most similar to those used at THF. When data were not available regarding the fraction of $\mathrm{NO}^{+}$and $\mathrm{O}_{2}^{+}$in the PTR-MS drift tube, the reported values of $\phi(93)$ were attributed entirely to $\mathrm{H}_{3} \mathrm{O}^{+}$reactions; however, contributions from reactions of the parent monoterpenes with $\mathrm{NO}^{+}$and $\mathrm{O}_{2}^{+}$should not be ruled out (see below). It is also important to note 
Table 6. Comparison between PTR-MS operating parameters employed at THF during summer of 2004 and in selected studies reported in the literature.

\begin{tabular}{llllll}
\hline$P_{\mathrm{DT}}(\mathrm{mbar})$ & $T_{\mathrm{DT}}(\mathrm{K})$ & $E\left(\mathrm{~V} \mathrm{~cm}^{-1}\right)$ & $E / N(\mathrm{Td})^{\mathrm{a}}$ & $\left.\mathrm{KE}_{\mathrm{ion}}(\mathrm{kJ} \mathrm{mole})^{-1}\right)^{\mathrm{b}}$ & Reference \\
\hline $1.8-2.1$ & $303-333$ & $60^{\mathrm{c}}$ & $120-150$ & $23.5-39.8$ & (Maleknia et al., 2007) \\
$1.8-2.1$ & $296^{\mathrm{d}}$ & $41.7-62.5$ & 142 & 32.8 & (Tani et al., 2004) \\
$2.005 \pm 0.005$ & 318 & 62.5 & 137 & 30.7 & This work \\
$\mathrm{ND}$ & $\mathrm{ND}$ & $\mathrm{ND}$ & 120 & $>23.3^{\mathrm{e}}$ & (Tani et al., 2003) \\
2.4 & $\mathrm{ND}$ & $\mathrm{ND}$ & 106 & $>18.4^{\mathrm{e}}$ & (Warneke et al., 2003) \\
1.47 & 298 & 0.08 & 0.22 & $3.7^{\mathrm{f}}$ & (Schoon et al., 2003) \\
2.2 & $\mathrm{ND}$ & $\mathrm{ND}$ & $\mathrm{ND}$ & $\mathrm{ND}$ & (Lee et al., 2006a,b) \\
\hline
\end{tabular}

a 1 TD (Townsend) $=10^{-17} \mathrm{~V} \mathrm{~cm}^{2} .{ }^{\mathrm{b}}$ Calculated from published values of $\mu_{0}$ in $\mathrm{N}_{2}$ (Dalton et al., 1976). ${ }^{\mathrm{c}}$ Drift tube length assumed to be $9.6 \mathrm{~cm} .{ }^{\mathrm{d}}$ Calculated from $P_{\mathrm{DT}}$ and $E / N$. ${ }^{\mathrm{e}}$ Assumed $T_{\mathrm{DT}}>21^{\circ} \mathrm{C} .{ }^{\mathrm{f}}$ Equivalent to thermal energy. ${ }^{\mathrm{g}}$ SIFT-MS; conditions correspond with flow tube. Abbreviations: DT, drift tube; ND, no data.

that fragmentation patterns are partly controlled by PTRMS operating conditions, which differed between studies; therefore, the yields reported in Table 5 may differ significantly from the actual yields obtained at THF. Table 6 gives the instrumental operating parameters, when available, corresponding with the fragmentation yields reported in Table 5 as well as the parameters employed at THF during summer 2004. Also given in Table 6 are mean $\mathrm{H}_{3} \mathrm{O}^{+}$kinetic energies, $\mathrm{KE}_{\mathrm{ion}}$, calculated from the tabulated operating parameters using Eq. (10) (McFarland et al., 1973),

$\mathrm{KE}_{\mathrm{ion}}=\frac{1}{2} \cdot m \cdot v_{\mathrm{d}}^{2}+\frac{1}{2} \cdot M_{\mathrm{b}} \cdot v_{\mathrm{d}}^{2}+\frac{3}{2} \cdot k_{\mathrm{B}} \cdot T$.

where $m$ and $M_{\mathrm{b}}$ are the $\mathrm{H}_{3} \mathrm{O}^{+}$and buffer gas molecular weights, respectively, $v_{\mathrm{d}}$ is the $\mathrm{H}_{3} \mathrm{O}^{+}$drift velocity, $T$ is the drift tube temperature, and $k_{\mathrm{B}}$ is the Boltzmann constant. The drift velocity was calculated using Eq. (11) (de Gouw and Warneke, 2007),

$v_{\mathrm{d}}=\frac{\mu_{0} \cdot N_{0} \cdot E}{N}$

where $\mu_{0}$ is the reduced $\mathrm{H}_{3} \mathrm{O}^{+}$mobility in the buffer gas, $N_{0}$ is the gas number density at standard temperature and pressure, $E$ is the electric field strength, and $N$ is the gas number density under the experimental conditions. The values of $\mathrm{KE}_{\text {ion }}$ in Table 6 allow $\mathrm{H}_{3} \mathrm{O}^{+}$-neutral collision energies to be compared between studies. Increasing $\mathrm{KE}_{\text {ion }}$ generally results in greater product ion fragmentation in the PTR-MS drift tube (c.f., Tani et al., 2003).

Although most previous studies reported values of $\phi(93)$ $\leq 1 \%$ from PTR-MS analysis and reaction with $\mathrm{H}_{3} \mathrm{O}^{+}$of the monoterpenes measured at THF, two showed $\phi(93)>1 \%$ from PTR-MS analysis of $\alpha$-pinene (Warneke et al., 2003; Maleknia et al., 2007), while one study reported $\phi(93)>1 \%$ from PTR-MS analysis of $\beta$-pinene (Warneke et al., 2003).
Impurities in liquid monoterpene standards employed in previous laboratory PTR-MS studies were measured at $m / z=93$ (Tani et al., 2003), and it is possible that uncharacterized impurities contributed to the maximum $\phi(93)$ value of $12 \%$ shown in Table 5. However, it is less likely that interference from impurities contributed to the high $\phi(93)$ values of $7 \%$ measured for $\alpha$ - and $\beta$-pinene in a GC-PTR-MS analysis of synthetic gas standards (Warneke et al., 2003). Therefore, we considered values of $\phi(93)$ significantly greater than $1 \%$ in quantifying possible interferences from $\alpha$ - and $\beta$-pinene fragmentation in the PTR-MS drift tube.

Corrections to the PTR-MS toluene mixing ratios were calculated for reactions of $\mathrm{H}_{3} \mathrm{O}^{+}$with the measured monoterpenes as shown in Sect. 2.2 using values of $\Delta_{\text {Mon }}$ from the GC-FID measurements; proton transfer reaction rate constants measured previously for toluene (Španel and Smith, 1998), $\alpha$ - and $\beta$-pinene (Tani et al., 2003); and integer values of $\phi(93)$ within the range of those reported previously (Table 5). To simplify the analysis we only considered corrections for which the value of $\phi(93)$ for $\alpha$-pinene was $\geq$ that for $\beta$-pinene, consistent with previous observations (Table 5). The PTR-MS rate data of Tani et al. (2003) were derived relative to the SIFT-MS rate constant for the reaction of $\mathrm{H}_{3} \mathrm{O}^{+}$with toluene measured by Španel and Smith (1998). The experimental rate constants agreed to within $15 \%$ error with the corresponding calculated collisional values (Španel and Smith, 1998; Schoon et al., 2003; Zhao and Zhang, 2004). For non-polar compounds with rate constants for reaction with $\mathrm{H}_{3} \mathrm{O}^{+}$that are close to the collisional limit the rate constants are expected to be independent of collision energy, which permits the use of thermal energy values for PTR-MS analyses (Keck et al., 2007). Thus, we assumed that the use of the SIFT-MS rate constant for toluene and the relative rate data of Tani et al. (2003) in our analysis was valid. 
Table 7. Comparison of reported yields of $m / z=93$ fragment ions associated with analysis of monoterpene oxidation products by PTR-MS and SIFT-MS.

\begin{tabular}{|c|c|c|c|c|}
\hline \multirow[b]{2}{*}{ Monoterpene } & \multirow[b]{2}{*}{ Oxidation Product } & \multicolumn{2}{|c|}{ Yield (\%) vs. Oxidant } & \multirow[b]{2}{*}{$\phi(93)(\%)^{\mathrm{a}}$} \\
\hline & & $\mathrm{OH}$ & $\mathrm{O}_{3}$ & \\
\hline \multirow[t]{4}{*}{$\alpha$-pinene } & pinonaldehyde & $47-83^{b}$ & $19-34^{\mathrm{c}}$ & $2^{\mathrm{d}}$ \\
\hline & & $28-87^{\mathrm{e}}$ & $16 \pm 3^{\mathrm{e}}$ & \\
\hline & $\alpha$-pinene oxide & & $5.4 \pm 0.6^{\mathrm{c}}$ & $9^{d}$ \\
\hline & & & $2^{\mathrm{e}}$ & \\
\hline$\beta$-pinene & $\mathrm{UnID}^{\mathrm{f}}$ & $<5^{\mathrm{b}}$ & & $100^{\mathrm{g}}$ \\
\hline$\beta$-myrcene & 4-vinyl-4-pentenal & $32-41^{b}$ & $49 \pm 8^{c}$ & $>70^{\mathrm{b}, \mathrm{g}, \mathrm{h}},>10^{\mathrm{c}, \mathrm{g}, \mathrm{h}}$ \\
\hline \multirow[t]{2}{*}{$\Delta^{3}$-carene } & caronaldehyde & $34 \pm 8^{\mathrm{i}}$ & $\leq 8^{\mathrm{i}}$ & $3^{d}$ \\
\hline & UnID & $>5^{\mathrm{b}}$ & & $100^{\mathrm{g}}$ \\
\hline ocimene $^{\mathrm{j}, \mathrm{k}}$ & 4-methyl-3,5-hexadienal ${ }^{1}$ & $<2$ & $<33$ & \\
\hline$d$-limonene & UnID & $<5^{\mathrm{b}}$ & & $100^{\mathrm{g}}$ \\
\hline$\gamma$-terpinene & UnID & $>5^{\mathrm{b}}$ & & $100^{\mathrm{g}}$ \\
\hline terpinolene & 4-methyl-3-cyclohexen-1-one & $43 \pm 7^{b}$ & $53 \pm 9^{c}$ & $47^{\mathrm{b}, \mathrm{g}, \mathrm{h}}, 9^{\mathrm{c}, \mathrm{g}, \mathrm{h}}$ \\
\hline
\end{tabular}

${ }^{a}$ From reaction with $\mathrm{H}_{3} \mathrm{O}^{+}$unless indicated otherwise. ${ }^{\mathrm{b}}$ (Lee et al., 2006b). ${ }^{\mathrm{c}}$ ( Lee et al., 2006a). ${ }^{\mathrm{d}}$ (Schoon et al., 2004). ${ }^{\mathrm{e}}$ (Atkinson et al., 2006). ${ }^{\mathrm{f}}$ UnID, unidentified oxidation products. ${ }^{\mathrm{g}} \mathrm{NO}^{+}$and $\mathrm{O}_{2}^{+}$abundances were not specified and may have contributed to reported fragmentation. ${ }^{\mathrm{h}}$ Assuming dehydration of the corresponding protonated oxidation product in the PTR-MS drift tube was the only source of the reported yield. ${ }^{\mathrm{i}}$ (Hakola et al., 1994). ${ }^{\mathrm{j}}$ cis-, trans- mixture. ${ }^{\mathrm{k}}$ (Reissell et al., 2002). ${ }^{1}$ Protonated molecular ion may dehydrate to a $m / z=93$ fragment ion as observed for other $110 \mathrm{amu}$ products (Lee et al., 2006a, b).

Table 4 presents quantitative data comparing the GC-FID and PTR-MS toluene measurements for several fragmentation corrections (treatments B-G) applied to the PTR-MS measurements. We defined fragmentation corrections that improved quantitative agreement between the GC-FID and PTR-MS measurements as those which (1) reduced the deviation of the simple least squares regression slope from unity and (2) increased the percentage of data for which both instruments agreed within combined measurement precisions. The minimum fragmentation correction used a value of $\phi(93)=1 \%$ for $\alpha$-pinene (treatment B). The best quantitative agreement between the two data sets was achieved with $\phi(93)=2 \%$ for $\alpha$-pinene and $1 \%$ for $\beta$-pinene (treatment C). For treatment $\mathrm{C}$ the median, 75th and 95th percentile corrections were $3 \%, 8 \%$ and $19 \%$, respectively; most of the corrections were within the PTR-MS measurement precision and were therefore insignificant. Values of $\phi(93)>5 \%$ for $\alpha$-pinene (e.g., treatment D) resulted in poorer quantitative agreement than for the uncorrected measurements. Thus, our data appear to be most consistent with small values of $\phi(93)$ for the measured monoterpenes and only a minor interference in the PTR-MS toluene measurements from reactions of monoterpenes with $\mathrm{H}_{3} \mathrm{O}^{+}$in the PTR-MS drift tube.
The calculated interference in the PTR-MS toluene measurements from reaction of $\mathrm{H}_{3} \mathrm{O}^{+}$with $\alpha$ - and $\beta$-pinene was highly correlated with $\Delta_{\text {Mon }}$ (Fig. 8) because of the relatively large measured abundances for those compounds. Were monoterpene fragmentation an important source of $m / z=93$ fragment ions in our instrument, the observed error in the PTR-MS toluene measurements (i.e., $\varepsilon$ PTR-MS) would also have closely tracked $\Delta_{\text {Mon }}$.

\subsubsection{Reactions with $\mathrm{O}_{2}^{+}$and $\mathrm{NO}^{+}$}

The $\mathrm{O}_{2}^{+}$and $\mathrm{NO}^{+}$ions are formed in low yield in the PTRMS ion source drift region (Hansel et al., 1995; de Gouw and Warneke, 2007), and their reactions with monoterpenes were shown to generate products that may interfere with the PTR-MS signal at $m / z=93$. Reactions of $\mathrm{O}_{2}^{+}$with $\alpha$ - and $\beta$ pinene, $d$-limonene, $\Delta^{3}$-carene, $\beta$-myrcene, and camphene in the flow tube of a SIFT-MS instrument produced fragment ion products with $\phi(93)>10 \%$ in all cases (Table 5) (Schoon et al., 2003). Similarly, reactions of $\mathrm{NO}^{+}$with $\beta$-myrcene yielded fragment ion products with $\phi(93)=22 \%$ (Schoon et al., 2003). Lower yields $(<5 \%)$ of $m / z=93$ products were measured for reactions of $\mathrm{NO}^{+}$with $\alpha$ - and $\beta$-pinene, $d$ - 
limonene, $\Delta^{3}$-carene, and camphene (Schoon et al., 2003). It is important to note that the absence of a strong electric field along the SIFT-MS flow tube results in substantially lower $\mathrm{H}_{3} \mathrm{O}^{+}$-neutral collision energies in SIFT-MS than in PTR-MS, as illustrated by values of $\mathrm{KE}_{\text {ion }}$ given in Table 6 . Furthermore, the stabilities of reaction intermediates are affected by the buffer gas, which differs between SIFT-MS and PTR-MS. Table 5 compares values of $\phi(81)$ measured for several monoterpenes by SIFT-MS, using $\mathrm{H}_{3} \mathrm{O}^{+}$as reagent ion, and PTR-MS, illustrating that the extent of monoterpene fragmentation (1) was greater at higher ratios of electric field strength to gas number density, $E / N$, in PTR-MS analyses and (2) was significantly greater, by a factor of $\sim 1.8 \pm 0.7(1 \sigma)$, in PTR-MS (with $E / N=120-150 \mathrm{Td}$ ) than in SIFT-MS analyses. Accordingly, fragmentation yields from reactions of monoterpenes with $\mathrm{O}_{2}^{+}$and $\mathrm{NO}^{+}$at THF likely were significantly higher than those observed by SIFT-MS. To partly account for higher values of $\phi(93)$ expected under our operating conditions than reported for the SIFT-MS analysis of Schoon et al. (2003), we performed calculations with the SIFT-MS fragmentation yields increased by a factor of 2 as discussed below.

Corrections to the PTR-MS toluene mixing ratios were calculated for reactions of $\mathrm{O}_{2}^{+}$with the measured monoterpenes in the PTR-MS drift tube (Table 4, treatment E). The calculations used rate constants and fragmentation patterns measured by SIFT-MS (Table 5) (Schoon et al., 2003). The experimental rate constants for reaction of $\mathrm{O}_{2}^{+}\left(\right.$and $\mathrm{NO}^{+}$) with the measured monoterpenes agreed to within $10 \%$ error with the corresponding calculated collisional values (Schoon et al., 2003). As described above (Sect. 3.3.1) for reaction of $\mathrm{H}_{3} \mathrm{O}^{+}$with toluene, $\alpha$ - and $\beta$-pinene the use of the SIFTMS rate constants for our analysis was assumed to be valid due to the non-polar nature of the monoterpenes. At THF the PTR-MS signal at $m / z=32$, which we attributed to $\mathrm{O}_{2}^{+}$, was typically $<1 \%$ of the $\mathrm{H}_{3} \mathrm{O}^{+}$signal during summer 2004 , and the median correction to the PTR-MS toluene mixing ratios was $<1 \%$, while the 95th percentile correction was $6 \%$. The quantitative agreement with the GC-FID measurements was slightly improved as compared with the uncorrected PTR-MS measurements (Table 4); however, the corrections were entirely within the PTR-MS measurement precision and therefore were insignificant. Increasing the values of $\phi(93)$ (Table 5) by a factor of 2 for $\mathrm{O}_{2}^{+}$reactions with the measured monoterpenes, yielding $\phi(93)=100 \%$ for $\alpha$ - and $\beta$ pinene, did not significantly influence the results for treatment E. Reactions of $\mathrm{O}_{2}^{+}$with $\alpha$ - and $\beta$-pinene were calculated to make the largest contribution to the $\mathrm{O}_{2}^{+}$-mediated monoterpene fragmentation interference because of the relatively large measured abundances and reported $\phi(93)$ for those compounds. The calculated fragmentation interference resulting from reactions of $\mathrm{O}_{2}^{+}$with the measured monoterpenes was highly correlated with $\Delta_{\text {Mon }}$ (Fig. 8). Applying corrections for $\mathrm{H}_{3} \mathrm{O}^{+}$and $\mathrm{O}_{2}^{+}$reactions together (treatment

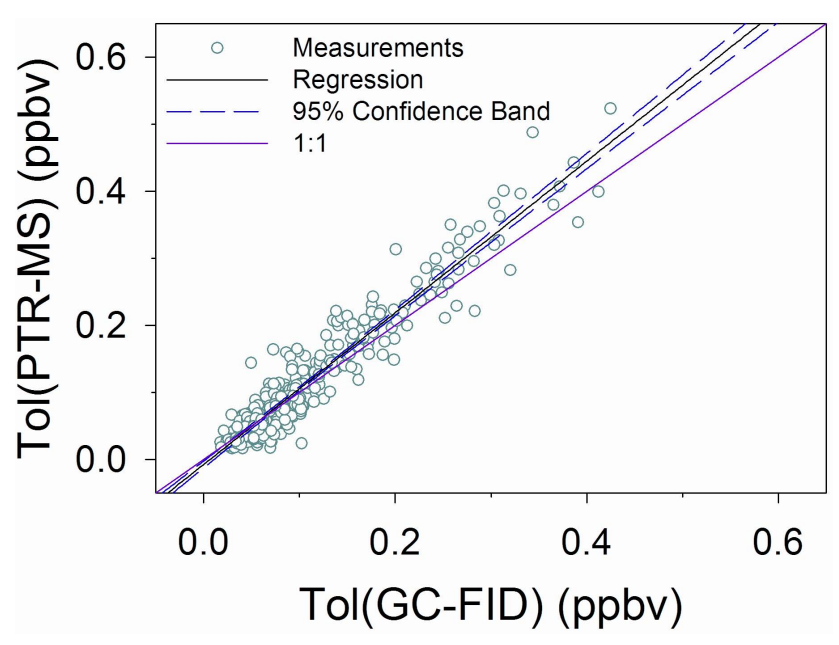

Fig. 7. Linear correlation between toluene measurements by GCFID and PTR-MS. The regression line and its confidence band were derived from a simple least squares analysis. The regression parameters are given in Table 4.

F) did not significantly affect agreement with the GC-FID measurements compared to when corrections were applied only for $\mathrm{H}_{3} \mathrm{O}^{+}$reactions. Our calculations suggest that reactions of monoterpenes with $\mathrm{O}_{2}^{+}$in the PTR-MS drift tube likely resulted in a minor additional source of $m / z=93$ fragment ions which did not interfere significantly with the measured toluene mixing ratios.

The PTR-MS signal at $m / z=31$, with contributions from ${ }^{15} \mathrm{~N}^{16} \mathrm{O}^{+}$and likely also the protonated molecular ion of formaldehyde $\left(\mathrm{H}_{3} \mathrm{CO}^{+}\right)$(de Gouw and Warneke, 2007), was typically $<0.001 \%$ of the $\mathrm{H}_{3} \mathrm{O}^{+}$signal. The corresponding ${ }^{14} \mathrm{~N}^{16} \mathrm{O}^{+}$signal at $m / z=30$ (unmeasured) was calculated to be $<0.3 \%$. Thus, considering that values of $\phi(93)$ for $\mathrm{NO}^{+}$ reactions are generally lower than those for $\mathrm{O}_{2}^{+}$(Table 5), reactions of monoterpenes with $\mathrm{NO}^{+}$in the PTR-MS drift tube likely did not significantly affect the measured $m / z=93$ ion current.

\subsection{Sources of interference from monoterpene oxidation products}

Table 7 gives yields of $m / z=93$ fragment ions from ozonolysis and photooxidation products of several monoterpenes. Reported formation yields for the oxidation products are also tabulated. Reactions of $\mathrm{H}_{3} \mathrm{O}^{+}$with oxidation products of $\alpha$-pinene and $\Delta^{3}$-carene were shown by SIFT-MS to give fragment ions at $m / z=93$ (Schoon et al., 2004). Products from ozonolysis of $\beta$-myrcene and terpinolene were detected by PTR-MS at $m / z=93$ in a recent laboratory chamber study (Lee et al., 2006a). In an investigation of monoterpene photochemistry by the same group (Lee et al., 2006b) photooxidation of $\beta$-myrcene, $\Delta^{3}$-carene, $\gamma$-terpinene and terpinolene gave products detected by PTR-MS at $m / z=93$ 

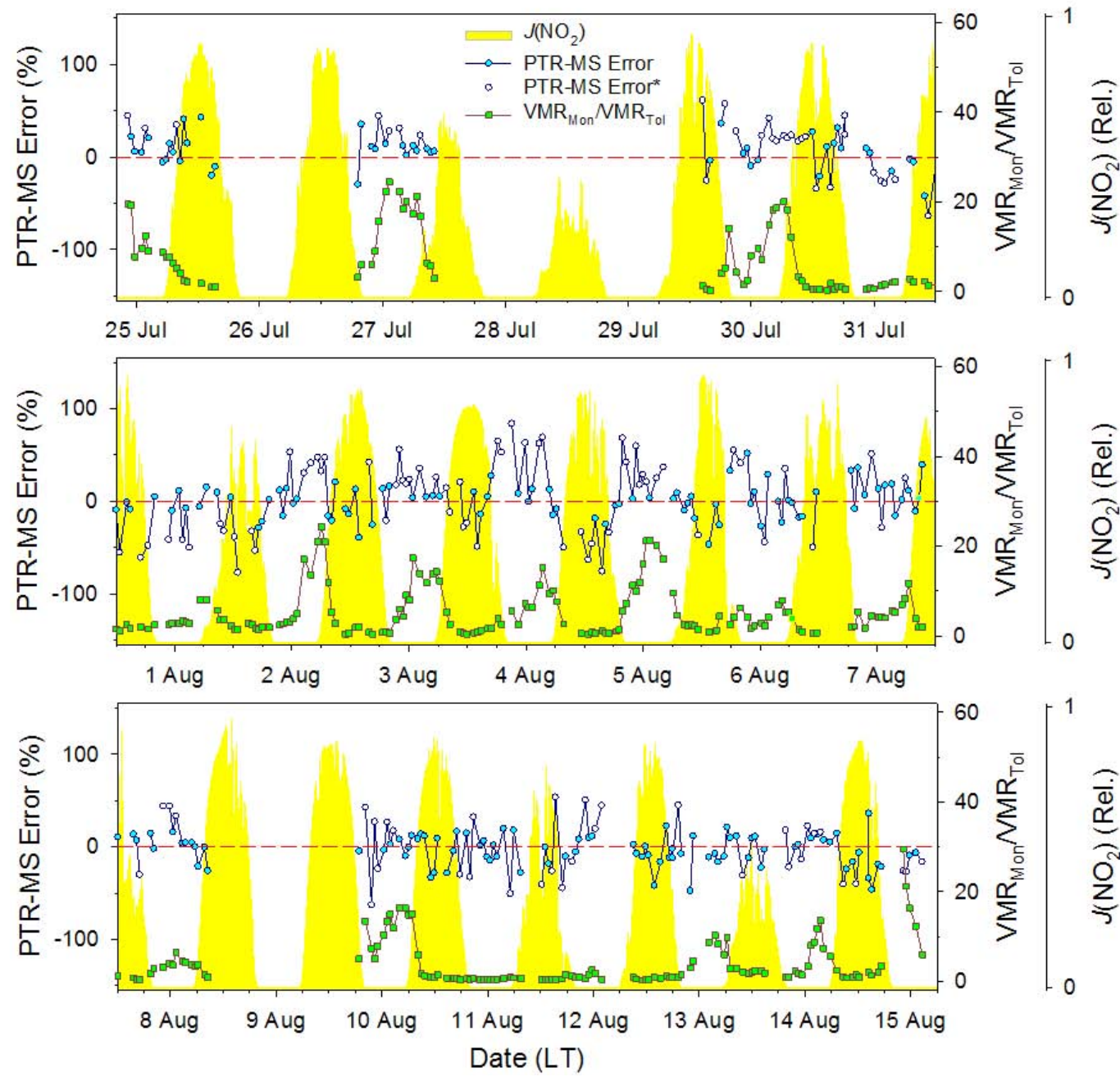

Fig. 8. Comparison between values of $\varepsilon_{\text {PTR-MS }}$ and $\Delta_{\text {Mon }}$ for merged GC-FID, PTR-MS data for the period from 24 July, 22:00 LT to 15 August, 06:00 LT. Values of $J\left(\mathrm{NO}_{2}\right)$ are show as in Fig. 5. *Open symbols correspond with times when the toluene measurements did not agree quantitatively within the combined precisions of the two instruments. The dotted line represents perfect agreement.

with $>5 \%$ molar yield, whereas photooxidation of $\beta$-pinene gave products detected at $m / z=93$ with $<5 \%$ molar yield. Ocimene undergoes similar ozonolysis and photooxidation chemistry as $\beta$-myrcene (Reissell et al., 2002), and therefore could potentially also yield an additional indirect source of $m / z=93$ fragment ions in PTR-MS analysis of monoterpenes during periods of active oxidation chemistry. In the following discussion we consider production of $m / z=93$ fragment ions from reactions of identified oxidation products of the monoterpenes measured at THF: pinonaldehyde, $\alpha$-pinene oxide and caronaldehyde.

\subsubsection{Ozonolysis products}

We used $\mathrm{O}_{3}$ measurements, together with published kinetic data for $\mathrm{O}_{3}$-monoterpene reactions and product formation yields (Table 7) to estimate production rates of pinonalde- hyde and $\alpha$-pinene oxide from $\alpha$-pinene ozonolysis, and caronaldehyde from $\Delta^{3}$-carene ozonolysis at THF. Unless otherwise indicated kinetic and product yield data from the most recent recommendations of the IUPAC Subcommittee for Gas Kinetic Data Evaluation (Atkinson et al., 2006) and from previous critical reviews (Atkinson, 1994, 1997) were used. Local conditions of pressure and temperature were used in all kinetic calculations; temperature dependencies have not been quantified for oxidation reactions of the majority of the monoterpenes. The calculated pinonaldehyde production rates, based on a yield of $16 \pm 3 \%$ (Table 7), ranged from $<0.001$ to $0.023 \pm 0.015 \mathrm{ppbv} \mathrm{hr}^{-1}$, with uncertainty governed mostly by contribution from the rate constant (Atkinson et al., 2006). The measured $\alpha$-pinene mixing ratios were linearly interpolated between consecutive GC-FID samples to estimate pinonaldehyde production rates at $5 \mathrm{~min}$ time resolution. Pinonaldehyde mixing ratios were estimated 
by summing the $5 \mathrm{~min}$ production rates over $1 \mathrm{~h}$ intervals, and ranged from $<0.001$ to $\sim 0.023 \mathrm{ppbv}$. Corrections to the PTR-MS toluene measurements for reactions of $\mathrm{H}_{3} \mathrm{O}^{+}$ with pinonaldehyde were calculated as described above for reactions of $\mathrm{H}_{3} \mathrm{O}^{+}$and $\mathrm{O}_{2}^{+}$with the parent monoterpenes. A value of $\phi(93)=0.02$ (Table 7) and the collisional proton transfer rate coefficient for pinonaldehyde (Schoon et al., 2004) resulted in negligible, 95 th percentile $<1 \%$, corrections to the PTR-MS toluene mixing ratios. For polar compounds with rate constants for reaction with $\mathrm{H}_{3} \mathrm{O}^{+}$that are close to the collisional limit, the rate constants are expected to decrease with increasing collision energy (Keck et al., 2007). However, large differences in rate constants are not expected between SIFT-MS and PTR-MS conditions for compounds with thermal ion-molecule rate constants that are close to the collisional limit (Wyche et al., 2005). We assumed that the rate constants of Schoon et al. (2004) provided upper limits that closely approximated the correct values in our analysis. The pinonaldehyde mixing ratio estimates bear considerable uncertainty since atmospheric loss processes, which may include a significant heterogeneous component (Liggio and Li, 2006), and transport were not taken into account. To partially account for the possibility of a higher value of $\phi(93)$ and greater pinonaldehyde accumulation in the sampled air, calculations were performed with the SIFT-MS value of $\phi(93)$ increased by a factor of 2 . With $\phi(93)=0.04$ the 95 th percentile correction remained $<1 \%$. Calculated production rates for $\alpha$-pinene oxide and caronaldehyde were considerably lower than for pinonaldehyde, $<0.003$ and $<0.001 \mathrm{ppbv} \mathrm{hr}^{-1}$ respectively, therefore it is likely that sampling of $\alpha$-pinene oxide and caronaldehyde from $\mathrm{O}_{3}$-initiated oxidation of $\alpha$-pinene and $\Delta^{3}$-carene did not significantly interfere in the PTR-MS toluene measurement. The calculated interference resulting from reaction of $\mathrm{H}_{3} \mathrm{O}^{+}$with pinonaldehyde, caronaldehyde and $\alpha$-pinene oxide was a function of (1) the mixing ratios of $\alpha$-pinene and $\Delta^{3}$-carene relative to that of toluene and (2) the local $\mathrm{O}_{3}$ mixing ratio. The $\mathrm{O}_{3}$ mixing ratio peaked in the late afternoon, whereas the relative abundances of $\alpha$-pinene and $\Delta^{3}$ carene tracked $\Delta_{\text {Mon }}$ and were highest toward the end of the night. The calculated interference resulting from reactions of $\mathrm{H}_{3} \mathrm{O}^{+}$with the monoterpene oxidation products showed a broad peak between the late evening (18:00 LT) and early morning (08:00 LT).

\subsubsection{Photooxidation products}

Because no measurements of $\mathrm{OH}$ have been made at THF to date the quantitative contribution of $\mathrm{OH}$ to monoterpene oxidation at THF is highly uncertain. We used a simple approximation of $\mathrm{OH}$ concentrations, together with published kinetic data (Atkinson, 1989, 1994; Atkinson et al., 2006) and formation yields for monoterpene photoxidation products (Table 7) to estimate production rates of pinonaldehyde and caronaldehyde from reactions of $\mathrm{OH}$ with $\alpha$-pinene and $\Delta^{3}$ - carene, respectively. Considering only daytime $\mathrm{OH}$ chemistry the time rate of change of the pinonaldehyde mixing ratio was approximated by Eq. (13):

$\frac{d[\text { Pinon }]}{d t}=P_{\text {Pinon }}-k_{\mathrm{OH}+\mathrm{Pinon}}^{\prime} \cdot[$ Pinon $]$,

where,

$P_{\text {Pinon }}=k_{\mathrm{OH}+\alpha-\mathrm{Pin}} \cdot f_{\mathrm{Pinon}} \cdot[\alpha-\mathrm{Pin}] \cdot[\mathrm{OH}]$,

$k_{\mathrm{OH}+\mathrm{Pinon}}^{\prime}=k_{\mathrm{OH}+\mathrm{Pinon}} \cdot[\mathrm{OH}]$.

Here $P_{\text {Pinon }}$ is the pinonaldehyde production rate, $f_{\text {Pinon }}$ denotes the formation yield of pinonaldehyde from reactions of $\mathrm{OH}$ with $\alpha$-pinene, and the bracketed terms represent concentrations where $\alpha$-Pin and Pinon stand for $\alpha$-pinene and pinonaldehyde, respectively. Pinonaldehyde mixing ratios were estimated by integrating Eq. (13) stepwise over twelve consecutive $5 \mathrm{~min}$ intervals $(1 \mathrm{hr})$, with the initial condition that $[$ Pinon $]=0$. For each $5 \mathrm{~min}$ interval, the terms $P_{\text {Pinon }}$ and $k_{\mathrm{OH}+\mathrm{Pinon}}^{\prime}$ were calculated from the interpolated $(5 \mathrm{~min}$ intervals) $\alpha$-pinene mixing ratios and a constant $\mathrm{OH}$ concentration of $2 \times 10^{6}$ molecules $\mathrm{cm}^{-3}$. The starting value of [Pinon] was taken from integration over the preceding interval. Caronaldehyde mixing ratios were estimated analogous to the pinonaldehyde estimates. Integration of Eq. (13) and the method used for estimating pinonaldehyde mixing ratios from $\alpha$-pinene ozonolysis are equivalent when the second term on the right side of Eq. (13) is excluded, which is appropriate for the slow $\mathrm{O}_{3}$-carbonyl reactions (c.f., Hakola et al., 1994). A similar method as outlined above was previously applied to estimate nighttime nitrate radical mixing ratios at the AIRMAP atmospheric monitoring station on Appledore Island, Maine (Ambrose et al., 2007). The approach is less appropriate here because the pinonaldehyde lifetime may be long enough for transport to partially govern its atmospheric mixing ratios. As for the pinonaldehyde levels estimated from $\alpha$-pinene ozonolysis, the mixing ratios estimated from $\mathrm{OH}$ oxidation bear large uncertainties. The calculated pinonaldehyde production rates ranged from $<0.001$ to $0.11 \pm 0.09 \mathrm{ppbv} \mathrm{hr}^{-1}$ based on an upper limit pinonaldehyde yield of $87 \pm 20 \%$ (Table 7 ). The $1 \mathrm{hr}$ integrated pinonaldehyde mixing ratios ranged from $<0.001$ to $\sim 0.10 \mathrm{ppbv}$, with maximum values occurring during the early morning hours, 06:00 to 07:30 LT. A value of $\phi(93)=0.02$ (Table 7) and the measured proton transfer rate coefficient for pinonaldehyde (Schoon et al., 2004) resulted in negligible, 95th percentile $<1 \%$, corrections to the PTR-MS toluene mixing ratios during the daytime hours. The calculated interference tracked the pinonaldehyde mixing ratio.

Measured $\mathrm{OH}$ concentrations were shown previously to be strongly correlated with solar ultraviolet radiation (UV) (Ehhalt and Rohrer, 2000; Rohrer and Berresheim, 2006). 
An approximation of $\mathrm{OH}$ that is consistent with the observed correlations between the $\mathrm{OH}$ concentration and solar UV would give lower $\mathrm{OH}$ concentrations and reduced oxidation rates at dawn, resulting in smaller corrections than for the case of a uniform $\mathrm{OH}$ concentration. Calculated production rates for caronaldehyde were slightly lower than for pinonaldehyde, $<0.09 \mathrm{ppbv} \mathrm{hr}^{-1}$, while the SIFT-MS value of $\phi(93)$ (Schoon et al., 2004) is only a factor of 1.5 higher for caronaldehyde (Table 7). Thus, it is likely that sampling of caronaldehyde from the oxidation of $\Delta^{3}$-carene by $\mathrm{OH}$ did not significantly interfere in the PTR-MS toluene analysis.

In addition to daytime photochemistry, reactions of $\mathrm{O}_{3}$ with alkenes were shown previously to generate $\mathrm{OH}$ in the dark (Atkinson, 1994). Yields of $\mathrm{OH}$ determined previously from ozonolysis of the monoterpenes measured at THF were typically large and ranged from $\leq 0.18$ for camphene to $1.06( \pm 50 \%)$ for $\Delta^{3}$-carene (Atkinson, 1997). Based on measured nighttime monoterpene and $\mathrm{O}_{3}$ mixing ratios and published kinetic data (Atkinson, 1994; Atkinson et al., 2006) and $\mathrm{OH}$ yields (Atkinson, 1997) the median nighttime $\mathrm{OH}$ production rate at THF was calculated to be $\sim 0.03 \mathrm{ppbv} \mathrm{hr}^{-1}$ and dominated by $\alpha$-pinene ozonolysis. For comparison, daytime $\mathrm{OH}$ production rates were calculated for the reaction sequence (R4) + (R5) using measurements of atmospheric pressure, $\mathrm{RH}$, and $J\left(\mathrm{NO}_{2}\right)$ and published kinetic data for reactions of singlet oxygen, $\mathrm{O}^{1} \mathrm{D}$, with $\mathrm{N}_{2}, \mathrm{O}_{2}$, and $\mathrm{H}_{2} \mathrm{O}$ (Atkinson et al., 2004):

$\mathrm{O}_{3}+h v \rightarrow \mathrm{O}^{1} \mathrm{D}+\mathrm{O}_{2}$,

$\mathrm{O}^{1} \mathrm{D}+\mathrm{H}_{2} \mathrm{O} \rightarrow 2 \mathrm{OH}$.

Values of $J\left(\mathrm{O}^{1} \mathrm{D}\right)$ were estimated from the $J\left(\mathrm{NO}_{2}\right)$ measurements using Eq. (16), which was derived from observations during summertime at a research site in northern Germany (Ehhalt and Rohrer, 2000):

$J\left(\mathrm{O}^{1} \mathrm{D}\right)=\left(\frac{J\left(\mathrm{NO}_{2}\right)}{1.6}\right)^{2}$.

The median daytime $\mathrm{OH}$ production rate from Reactions (R4) and (R5) was calculated to be $\sim 0.1 \mathrm{ppbv} \mathrm{hr}^{-1}$, and may represent $<25 \%$ of the total daytime $\mathrm{OH}$ production (Rohrer and Berresheim, 2006). Thus, it is expected that $\mathrm{OH}$ made a small but perhaps non-negligible contribution to nighttime monoterpenes oxidation at THF. Published mechanisms for the oxidation of $\alpha$-pinene by $\mathrm{OH}$ require values of VMR(NO)/VMR(Mon) $\geq 1$ for maximal yield of pinonaldehyde (Pinho et al., 2007). Pinonaldehyde yields significantly lower than the values given in Table 7 were observed previously from photooxidation of $\alpha$-pinene in the absence of NO (Hatakeyama et al., 1991). Nighttime NO levels at THF were typically below the $0.06 \mathrm{ppbv}$ instrumental LOD, 95th percentile $<0.15 \mathrm{ppbv}$, and values of VMR(NO)/VMR(Mon) were typically $<0.01,95$ th percentile $<0.21$. Thus, nighttime production of pinonaldehyde and caronaldehyde (by analogy) was expected to be significantly lower than daytime production despite higher monoterpene mixing ratios during nighttime. In conclusion the above analysis suggests that products of $\mathrm{OH}$-initiate monoterpene oxidation did not interfere with the PTR-MS toluene measurement at THF.

\subsection{Additional contributions to PTR-MS signal at $m / z=93$}

\subsubsection{Reactions with $\mathrm{H}_{3} \mathrm{O}^{+}\left(\mathrm{H}_{2} \mathrm{O}\right)$}

It is likely that the proton affinities of the monoterpenes measured at THF are sufficiently high for those compounds to react with $\mathrm{H}_{3} \mathrm{O}^{+}\left(\mathrm{H}_{2} \mathrm{O}\right)$ in the PTR-MS drift tube (Fernandez et al., 1998; Lindinger et al., 1998b; Tani et al., 2004). Such reactions could provide a source of $m / z=93$ fragment ions in addition to those discussed above. However, in our analysis we did not consider reaction of monoterpenes with $\mathrm{H}_{3} \mathrm{O}^{+}\left(\mathrm{H}_{2} \mathrm{O}\right)$ because of its low measured ion current relative to that of $\mathrm{H}_{3} \mathrm{O}^{+}$and the lack of relevant kinetic and product data. We estimated that at most, reaction of the measured monoterpenes with $\mathrm{H}_{3} \mathrm{O}^{+}\left(\mathrm{H}_{2} \mathrm{O}\right)$ would increase the $m / z=93$ yields by on average $10 \%$ above the yields from reaction with $\mathrm{H}_{3} \mathrm{O}^{+}$alone, assuming equal rate constants and yields for reactions with $\mathrm{H}_{3} \mathrm{O}^{+}$and $\mathrm{H}_{3} \mathrm{O}^{+}\left(\mathrm{H}_{2} \mathrm{O}\right)$. Because the proton affinity of $\left(\mathrm{H}_{2} \mathrm{O}\right)_{2}\left(808 \mathrm{~kJ} \mathrm{~mole}^{-1}\right)$ is much higher than that of $\mathrm{H}_{2} \mathrm{O}\left(691 \mathrm{~kJ}\right.$ mole $\left.{ }^{-1}\right)$ (Blake et al., 2009), which results in less exothermic proton transfer reactions for $\mathrm{H}_{3} \mathrm{O}^{+}\left(\mathrm{H}_{2} \mathrm{O}\right)$ compared with $\mathrm{H}_{3} \mathrm{O}^{+}$, it is likely that the $m / z=93$ yields from reaction of $\mathrm{H}_{3} \mathrm{O}^{+}\left(\mathrm{H}_{2} \mathrm{O}\right)$ with the monoterpenes measured at THF are significantly lower than those from reaction with $\mathrm{H}_{3} \mathrm{O}^{+}$. Available kinetic data suggest that proton transfer rate constants for $\mathrm{H}_{3} \mathrm{O}^{+}\left(\mathrm{H}_{2} \mathrm{O}\right)$ are generally slower than those for $\mathrm{H}_{3} \mathrm{O}^{+}$(Smith and Španel, 2005).

\subsubsection{Chloroacetone and proton-bound ethanol dimer $\left(\left((\mathbf{E t O H})_{2}+\mathbf{H}\right)^{+}\right)$}

For completeness it should be noted that, in addition to toluene and fragment ions produced from monoterpenes and their oxidation products, chloroacetone was also shown to yield an $\mathrm{m} / z=93$ ion $\left(\mathrm{C}_{3} \mathrm{H}_{6} \mathrm{ClO}^{+}\right)$when measured via PTRMS (Warneke et al., 2003). Also, two laboratory studies have attributed PTR-MS measurements of $\mathrm{m} / \mathrm{z}=93$ ions to protonbound ethanol dimers $\left(\mathrm{C}_{4} \mathrm{H}_{13} \mathrm{O}_{2}^{+} ;\left((\mathrm{EtOH})_{2}+\mathrm{H}\right)^{+}\right)$(Steeghs et al., 2004; Maleknia et al., 2007). Chloroacetone is not commonly measured in the atmosphere, and its mixing ratios are expected to be low (Warneke et al., 2003). The conditions employed in the laboratory PTR-MS EtOH measurements were not representative of ambient air. We found the $m / z=47$ signal to be unreliable for measurement of EtOH at THF due to low sensitivity and significant interferences. Interferences in the PTR-MS $m / z=93$ signal from chloroacetone and $\left((\mathrm{EtOH})_{2}+\mathrm{H}\right)^{+}$cannot be fully evaluated form our data, but they are not likely to be significant. 


\section{Summary}

In the analysis of atmospheric VOCs by PTR-MS, toluene is quantified as its protonated molecular ion at $m / z=93$. Previous laboratory PTR-MS and SIFT-MS studies suggested additional sources of $m / z=93$ ions associated with sampling and analysis of several monoterpenes, including fragmentation of the parent monoterpenes and their carbonyl oxidation products in the PTR-MS drift tube (Schoon et al., 2003; Tani et al., 2003; Warneke et al., 2003; Schoon et al., 2004, Tani et al., 2004; Lee et al., 2006a, b; Maleknia et al., 2007). To date, studies dedicated to evaluating the importance of these additional $m / z=93$ sources in ambient air have not appeared in the literature; in general, PTR-MS validation studies have not been carried out in forested environments where the largest quantities of monoterpenes and their oxidation products are expected to be encountered.

We conducted a quantitative comparison among GC-FID and PTR-MS toluene measurements made at the AIRMAP THF atmospheric monitoring station during the summer of 2004. Concurrent measurements of monoterpenes, including $\alpha$ - and $\beta$-pinene, camphene, $\Delta^{3}$-carene, and $d$-limonene, by GC-FID demonstrated that the monoterpene abundance regularly greatly exceeded that of toluene during the nighttime hours under calm conditions. The data presented a unique test of PTR-MS specificity for toluene measurement in an atmospheric environment heavily influenced by biogenic monoterpene emissions.

The GC-FID and PTR-MS toluene measurements ranged between $<0.015$ and $\sim 0.5$ ppbv and were generally in good quantitative agreement as observed in previous comparison studies. An overall minor $(\sim 13 \%)$ positive bias was observed for the PTR-MS measurements, but did not correlate strongly with coincident monoterpene enhancements, as would be expected if monoterpene fragmentation contributed significantly to the PTR-MS signal at $m / z=93$.

Potential sources of $m / z=93$ fragment ions associated with sampling and analysis of monoterpenes by PTR-MS were quantified and included reactions of the measured monoterpenes and some of their atmospheric oxidation products with $\mathrm{H}_{3} \mathrm{O}^{+}, \mathrm{O}_{2}^{+}$and $\mathrm{NO}^{+}$in the PTR-MS drift tube. Their significance was evaluated in terms of corresponding calculated corrections to the PTR-MS toluene mixing ratios. Yields of $m / z=93$ fragment ions, $\phi(93)$, and kinetic parameters for the associated ion-molecule reactions were taken from the PTR-MS and SIFT-MS literature. Kinetic parameters for reactions of the monoterpenes and their primary carbonyl oxidation products with $\mathrm{O}_{3}$ and hydroxyl radical, together with measured $\mathrm{O}_{3}$ mixing ratios and an assumed constant daytime $\mathrm{OH}$ concentration were used to estimate mixing ratios for the carbonyls. Our data were most consistent with $\phi(93)$ values of a few percent for reactions of $\mathrm{H}_{3} \mathrm{O}^{+}$with $\alpha$ - and $\beta$-pinene, which resulted in mostly insignificant corrections to the PTR-MS toluene measurements. Negligibly small corrections to the PTR-MS measurements were also calculated for reactions of the measured monoterpenes with $\mathrm{O}_{2}^{+}$and $\mathrm{NO}^{+}$. Likewise, levels of the monoterpene oxidation products pinonaldehyde, $\alpha$-pinene oxide and caronaldehyde were estimated to be too low to significantly interfere with the PTR-MS toluene measurement. Applying the calculated fragmentation corrections to our data would increase by $<10 \%$ the number of PTR-MS toluene measurements that agreed quantitatively with the GC-FID measurements.

We conclude that the PTR-MS bias was likely driven by a relatively large and variable toluene background in the PTRMS instrument, although the precise contribution was difficult to quantify and thus was not corrected for in this analysis. Subsequent to the ICARTT campaign an improved catalytic converter was developed in our laboratory which yielded significantly lower, more stable background levels for most ions, including $m / z=93$. The design and performance characteristics of the new catalytic converter for PTRMS measurements will be described in detail in the Ph.D. thesis of K. Haase.

Our results suggest that with our PTR-MS operating conditions, under the atmospheric conditions encountered at THF, interferences in PTR-MS toluene measurement associated with monoterpene sampling is not significant. This work extends the range of atmospheric conditions under which the specificity of the PTR-MS technique for atmospheric VOC measurement has been validated. The data interpretation methods presented here should be more generally applicable for verifying the extent of analyte fragmentation in PTRMS analysis of ambient air samples. An alternative, complementary approach to our methodology for interference estimation would involve direct measurement of fragmentation yields for the relevant monoterpenes. The resources necessary for such measurements were not available to us at the time this work was performed. Measurements under PTRMS operating conditions of kinetic parameters and ion product yields for reactions of $\mathrm{H}_{3} \mathrm{O}^{+}\left(\mathrm{H}_{2} \mathrm{O}\right), \mathrm{NO}^{+}$, and $\mathrm{O}_{2}^{+}$with common atmospheric analytes, including monoterpene compounds, would be highly beneficial to the type of analysis presented here.

\section{Supplementary material related to this article is available online at: http://www.atmos-meas-tech.net/3/959/2010/ amt-3-959-2010-supplement.amt-2009-97-supplement. pdf.}

Acknowledgements. Financial support for this work was provided to UNH through grant \#NA06OAR4600189 from the Office of Oceanic and Atmospheric Research at the National Oceanic and Atmospheric Administration. We are thankful for the helpful comments of the two anonymous reviewers.

Edited by: D. Riemer 


\section{References}

Ambrose, J. L., Mao, H., Mayne, H. R., Stutz, J., Talbot, R., and Sive, B. C.: Nighttime nitrate radical chemistry at Appledore Island, Maine during the 2004 International Consortium for Atmospheric Research on Transport and Transformation, J. Geophys. Res., 112, D21302, doi:10.1029/2007JD008756, 2007.

Andreae, M. O. and Merlet, P.: Emission of trace gases and aerosols from biomass burning, Global Biogeochem. Cy., 15, 955-966, 2001.

Apel, E. C., Calvert, J. G., Greenberg, J. P., Riemer, D., Zika, R., Kleindienst, T. E., Lonneman, W. A., Fung, K., and Fujita, E.: Generation and validation of oxygenated volatile organic carbon standards for the 1995 Southern Oxidants Study Nashville Intensive, J. Geophys. Res., 103, 22281-22944, 1998.

Apel, E. C., Hills, A. J., Leub, R., Zindel, S., Eisele, S., and Riemer, D. D.: A fast-GC/MS system to measure $\mathrm{C}_{2}$ to $\mathrm{C}_{4}$ carbonyls and methanol aboard aircraft, J. Geophys. Res., 108, D20, 8794, doi:10.1029/2002JD003199, 2003.

Atkinson, R.: Kinetics and mechanisms of the gas-phase reactions of the hydroxyl radical with organic compounds, J. Phys. Chem. Ref. Data, 1, 1-246, 1989.

Atkinson, R.: Gas-phase tropospheric chemistry of organic compounds, J. Phys. Chem. Ref. Data Monogr., 2, 1-216, 1994.

Atkinson, R.: Gas-phase tropospheric chemistry of volatile organic compounds: 1. Alkanes and alkenes, J. Phys. Chem. Ref. Data, 26, 215-290, 1997.

Atkinson, R. and Arey, J.: Gas-phase tropospheric chemistry of biogenic volatile organic compounds: a review, Atmos. Environ, 37 , S2, S197-S219, 2003.

Atkinson, R., Baulch, D. L., Cox, R. A., Crowley, J. N., Hampson, R. F., Hynes, R. G., Jenkin, M. E., Rossi, M. J., and Troe, J.: Evaluated kinetic and photochemical data for atmospheric chemistry: Volume $\mathrm{I}$ - gas phase reactions of $\mathrm{O}_{\mathrm{x}}, \mathrm{HO}_{\mathrm{x}}, \mathrm{NO}_{\mathrm{x}}$ and $\mathrm{SO}_{\mathrm{x}}$ species, Atmos. Chem. Phys., 4, 1461-1738, doi:10.5194/acp-41461-2004, 2004.

Atkinson, R., Baulch, D. L., Cox, R. A., Crowley, J. N., Hampson, R. F., Hynes, R. G., Jenkin, M. E., Rossi, M. J., Troe, J., and IUPAC Subcommittee: Evaluated kinetic and photochemical data for atmospheric chemistry: Volume II - gas phase reactions of organic species, Atmos. Chem. Phys., 6, 3625-4055, doi:10.5194/acp-6-3625-2006, 2006.

Blake, R. S., Monks, P. S., and Ellis, A. M.: Proton-Transfer Reaction Mass Spectrometry, Chem. Rev., 109, 861-896, 2009.

Christian, T. J., Kleiss, B., Yokelson, R. J., Holzinger, R., Crutzen, P. J., Hao, W. M., Shirai, T., and Blake, D. R.: Comprehensive laboratory measurements of biomass-burning emissions: 2. First intercomparison of open-path FTIR, PTRMS, and GC-MS/FID/ECD, J. Geophys. Res., 109, D02311, doi:10.1029/2003JD003874, 2004.

Dalton, I., Albritton, D. L., Lindinger, W., and Pahl, M.: Mobilities of $\mathrm{CO}_{2}^{+}, \mathrm{N}_{2} \mathrm{H}^{+}, \mathrm{H}_{3} \mathrm{O}^{+}, \mathrm{H}_{3} \mathrm{O}^{+} \mathrm{H}_{2} \mathrm{O}$, and $\mathrm{H}_{3} \mathrm{O}^{+}\left(\mathrm{H}_{2} \mathrm{O}\right)_{2}$ ions in $\mathrm{N}_{2}$, J. Chem. Phys., 65, 5028-5030, 1976.

de Bievre, P. and Taylor, P. D. P.: Table of isotopic compositions of the elements, Int. J. Mass Spectrom., 123, 149-166, 1993.

de Gouw, J. A., Goldan, P. D., Warneke, C., Kuster, W. C., Roberts, J. M., Marchewka, M., Bertman, S. B., Pszenny, A. A. P., and Keene, W. C.: Validation of proton transfer reaction-mass spectrometry (PTR-MS) measurements of gas-phase organic compounds in the atmosphere during the New England Air Qual- ity Study (NEAQS) in 2002, J. Geophys. Res., 108, D21, 4682, doi:10.1029/2003JD003863, 2003a.

de Gouw, J. and Warneke, C.: Measurements of volatile organic compounds in the Earth's atmosphere using proton-transferreaction mass spectrometry, Mass. Spectrom. Rev., 26, 223-257, 2007.

de Gouw, J., Warneke, C., Karl, T., Eerdekens, G., van der Veen, C., and Fall, R.: Sensitivity and specificity of atmospheric trace gas detection by proton-transfer-reaction mass spectrometry, Int. J. Mass Spectrom., 223/224, 365-382, 2003b.

de Gouw, J. A., Warneke, C., Stohl, A., Wollny, A. G., Brock, C. A., Cooper, O. R., Holloway, J. S., Trainer, M., Fehsenfeld, F. C., Atlas, E. L., Donnelly, S. G., Stroud, V., and Lueb, A.: Volatile organic compounds composition of merged and aged forest fire plumes from Alaska and western Canada, J. Geophys. Res., 111, D10303, doi:10.1029/2005JD006175, 2006.

Ehhalt, D. H. and Rohrer, F.: Dependence of the $\mathrm{OH}$ concentration on solar UV, J. Geophys. Res., 105, 3565-3571, 2000.

Fernandez, M. T., Williams, C., Mason, R. S., and Costa Cabral, B. J.: Experimental and theoretical proton affinity of limonene, J. Chem. Soc., Faraday Trans., 94, 1427-1430, 1998.

Geron, C., Rasmussen, R., Arnts, R. R., and Guenther, A.: A review and synthesis of monoterpene speciation from forests in the United States, Atmos. Environ., 34, 1761-1781, 2000.

Graedel, T. E.: Terpenoids in the atmosphere, Rev. Geophys., 17, 937-947, 1979.

Guenther, A. B., Zimmerman, P. R., Harley, P. C., Monson, R. K., and Fall, R.: Isoprene and monoterpene emission rate variability: model evaluations and sensitivity analyses, J. Geophys. Res., 98, D7, 12609-12617, 1993.

Hakola, H., Arey, J., Aschmann, S. M., and Atkinson, R.: Product formation from the gas-phase reactions of $\mathrm{OH}$ radicals and $\mathrm{O}_{3}$ with a series of monoterpenes, J. Atmos. Chem., 18, 75-102, 1994.

Hansel, A., Jordan, A., Holzinger, R., Prazeller, P., Vogel, W., and Lindinger, W.: Proton transfer reaction mass spectrometry: online trace gas analysis at the ppb level, Int. J. Mass. Spectrom. Ion Proc., 149/150, 609-619, 1995.

Hatakeyama, S., Izumi, K., Fukuyama, T., Akimoto, H., and Washida, N.: Reactions of $\mathrm{OH}$ with alpha-pinene and betapinene in air - estimate of global CO production from the atmospheric oxidation of terpenes, J. Geophys. Res., 96, D1, 947-958, 1991.

Hayward, S., Hewitt, C. N., Sartin, J. H., and Owen, S. M.: Performance characteristics and applications of a proton transfer reaction-mass spectrometer for measuring volatile organic compounds in ambient air, Environ. Sci. Technol., 36, 1554-1560, 2002.

Heiden, A. C., Kobel, K., Komenda, M., Koppmann, R., Shao, M., and Wildt, J.: Toluene emissions from plants, Geophys. Res. Lett., 26, 1283-1286, 1999.

Helmig, D., Klinger, L. F., Guenther, A., Vierling, L., Geron, C., and Zimmerman, P.: Biogenic volatile organic compound emissions (BVOCs) I. Identifications from three continental sites in the US, Chemosphere, 38, 2163-2187, 1998.

Hewitt, C. N., Hayward, S., and Tani, A.: The application of proton transfer reaction-mass spectrometry (PTR-MS) to the monitoring and analysis of volatile organic compounds in the atmosphere, J. Environ. Monit., 5, 1-7, 2003. 
Holzinger, R., Sandoval-Soto, L., Rottenberger, S., Crutzen, P. J., and Kesselmeier, J.: Emissions of volatile organic compounds from Quercus ilex L. measured by Proton Transfer Reaction Mass Spectrometry under different environmental conditions, J. Geophys. Res., 105, 20573-20579, 2000.

Hurley, M. D., Sokolov, O., Wallington, T. J., Takekawa, H., Karasawa, M., Koltz, B., Barnes, I., and Becker, K. H.: Organic aerosol formation during the atmospheric degradation of toluene, Environ. Sci. Technol., 35, 1358-1366, 2001.

Justice, D., Deely, A. K., and Rubin, F.: New Hampshire Land Cover Assessment: Final Report, Complex Systems Research Center, University of New Hampshire, Durham, NH, Rep., 42pp., 2002.

Karl, T., Apel, E., Hodzic, A., Riemer, D. D., Blake, D. R., and Wiedinmyer, C.: Emissions of volatile organic compounds inferred from airborne flux measurements over a megacity, Atmos. Chem. Phys., 9, 271-285, doi:10.5194/acp-9-271-2009, 2009.

Kato, S., Miyakawa, Y., Kaneko, T., and Kajii, Y.: Urban air measurements using PTR-MS in Tokyo area and comparison with GC-FID measurements, Int. J. Mass Spectrom., 235, 103-110, 2004.

Keck, L., Oeh, U., and Hoeschen, C.: Corrected equation for the concentrations in the drift tube of a proton transfer reaction-mass spectrometer (PTR-MS), Int. J. Mass Spectrom., 264, 92-95, 2007.

Kuster, W. C., Jobson, B. T., Karl, T., Riemer, D., Apel, E., Goldan, P. D., and Fehsenfeld, F. C.: Intercomparison of volatile organic carbon measurement techniques and data at La Porte during TexAQS2000 Air Quality Study, Environ. Sci. Technol., 38, 221228, 2004.

Lee, A., Goldstein, A. H., Keywood, M. D., Gao, S., Varutbangkul, V., Bahreini, R., Ng., N. L., Flagan, R. C., and Seinfeld, J. H.: Gas-phase products and secondary aerosol yields from the ozonolysis of ten different terpenes, J. Geophys. Res., 111, D07302, doi:10.1029/2005JD006437, 2006a.

Lee, A., Goldstein, A. H., Kroll, J. H., Ng, N. L., Varutbangkul, V., Flagan, R. C., and Seinfeld, J. H.: Gas-phase products and secondary aerosol yields from the photooxidation of 16 different terpenes, J. Geophys. Res., 111, D17305, doi:10.1029/2006JD007050, 2006b.

Lide, D. R.: CRC Handbook of Chemistry and Physics, 88th ed., CRC Press, Boca Raton, FL, USA, 2008.

Liggio, J. and Li, S.-M.: Reactive uptake of pinonaldehyde on acidic aerosols, J. Geophys. Res., 111, D24303, doi:10.1029/2005JD006978, 2006.

Lindinger, W., Hansel, A., and Jordan, A.: On-line monitoring of volatile organic compounds at pptv levels by means of protontransfer-reaction mass spectrometry (PTR-MS) - Medical applications, food control and environmental research, Int. J. Mass Spectrom., 173, 191-241, 1998a.

Lindinger, W., Hansel, H., and Jordan, A.: Proton-transfer-reaction mass spectrometry (PTR-MS): on-line monitoring of volatile organic compounds at pptv levels, Chem. Soc. Rev., 27, 347-354, 1998b.

Maleknia, S. D., Bell, T. L., and Adams, M. A.: PTR-MS analysis of reference and plant-emitted volatile organic compounds, Int. J. Mass Spectrom., 262, 203-210, 2007.

McFarland, M., Albritton, D. L., Fehsenfeld, F. C., Ferguson, E. E., and Schmeltekopf, A. L.: Flow-drift technique for ion mobility and ion-molecule reaction rate constant measurements. II. Positive ion reactions of $\mathrm{N}^{+}, \mathrm{O}^{+}$, and $\mathrm{N}_{2}^{+}$with $\mathrm{O}_{2}$ and $\mathrm{O}^{+}$with $\mathrm{N}_{2}$ from thermal to $\sim 2 \mathrm{eV}$, J. Chem. Phys., 59, 6620-6628, 1973.

Ollinger, S. V., Aber, J. D., and Federer, C. A.: Estimating regional forest productivity and water yield using an ecosystem model linked to a GIS, Landscape Ecol., 13, 323-334, 1998.

Parrish, D. D., Stohl, A., Forster, C., Atlas, E. L., Blake, D. R., Goldan, P. D., Kuster, W. C., and de Gouw, J. A.: Effects of mixing on evolution of hydrocarbon ratios in the troposphere, J. Geophys. Res., 112, D10S34, doi:10.1029/2006JD007583, 2007.

Pinho, P. G., Pio, C. A., Carter, W. P. L., and Jenkin, M. E.: Evaluation of $\alpha$-and $\beta$-pinene degradation in the detailed tropospheric chemistry mechanism, MCM v3.1, using environmental chamber data, J. Atmos. Chem., 57, 171-202, 2007.

Reissell, A., Aschmann, S. M., Atkinson, R., and Arey, J.: Products of the $\mathrm{OH}$ radical- and $\mathrm{O}_{3}$-initiated reactions with myrcene and ocimene, J. Geophys. Res., 107, D12, 4138, 10.1029/2001JD001234, 2002.

Rinne, J., Ruuskanen, R. M., Reissell, A., Taipale, R., Hakola, H., and Kulmala, M.: On-line PTR-MS measurements of atmospheric concentrations of volatile organic compounds in a European boreal forest ecosystem, Boreal Environ. Res., 10, 425-436, 2005.

Roberts, J. M., Fehsenfeld, F. C., Liu, S. C., Bollinger, M. J., Hahn, C., Albritton, D. L., and Sievers, R. E.: Measurements of aromatic hydrocarbon ratios and $\mathrm{NO}_{\mathrm{x}}$ concentrations in the rural troposphere: Estimates of air mass photochemical age and $\mathrm{NO}_{\mathrm{x}}$ removal rate, Atmos. Environ., 18, 2421-2432, 1984.

Roberts, J. M., Hahn, C. J., Fehsenfeld, F. C., Warnock, J. M., Albritton, D. L., and Sievers, R. E.: Monoterpene hydrocarbons in the nighttime troposphere, Environ. Sci. Tech., 19, 364-369, 1985.

Rogers, T. M., Grimsrud, E. P., Herndon, S. C., Jayne, J. T., Kolb, C. E., Allwine, E., Westberg, H., Lamb, B. K., Zavala, M., Molina, L. T., Molina, M. J., and Knighton, W. B.: On-road measurements of volatile organic compounds in the Mexico City metropolitan area using proton transfer reaction mass spectrometry, Int. J. Mass. Spectrom., 252, 26-37, 2006.

Rohrer, F. and Berresheim, H.: Strong correlation between levels of tropospheric hydroxyl radicals and solar ultraviolet radiation, Nature, 442, 184-187, 2006.

Russo, R. S., Zhou, Y., White, M. L., Mao, H., Talbot, R., and Sive, B. C.: Multi-year (2004-2008) record of nonmethane hydrocarbons and halocarbons in New England: seasonal variations and regional sources, Atmos. Chem. Phys., 10, 4909-4929, doi:10.5194/acp-10-4909-2010, 2010.

Schauer, J. J., Kleeman, M. J., Cass, G. R., and Simoneit, B. R. T.: Measurement of emissions from air pollution sources. 5. $\mathrm{C}_{1^{-}}$ $\mathrm{C}_{32}$ organic compounds from gasoline-powered motor vehicles, Environ. Sci. Technol., 36, 1169-1180, 2002.

Schoon, N., Amelynck, C., Vereecken, L., and Arijs, E.: A selected ion flow tube study of the reactions of $\mathrm{H}_{3} \mathrm{O}^{+}, \mathrm{NO}^{+}$and $\mathrm{O}_{2}^{+}$with a series of monoterpenes, Int. J. Mass Spectrom., 229, 231-240, 2003.

Schoon, N, Amelynck, C., Vereecken, L., Coeckelberghs, H., and Arijs, E.: A selected ion flow tube study of the reactions of $\mathrm{H}_{3} \mathrm{O}^{+}, \mathrm{NO}^{+}$and $\mathrm{O}_{2}^{+}$with some monoterpene oxidation products, Int. J. Mass Spectrom., 239, 7-16, 2004.

Singh, H. B. and Zimmerman, P. B.: Atmospheric distribution and 
sources of nonmethane hydrocarbons, in: Gaseous Pollutants: Characterization and Cycling, John Wiley \& Sons, Inc., New York, NY, USA, 177-235, 1992.

Sive, B. C.: Atmospheric nonmethane hydrocarbons: Analytical methods and estimated hydroxyl radical concentrations, University of California, Irvine, Irvine, Ph.D. thesis, 1998.

Sive, B. C., Zhou, Y., Troop, D., Li, Y., Little, W., Wingenter, O. W., Russo, R. S., Varner, R. K., and Talbot, R. W.: Development of a cryogen-free concentration system for measurements of volatile organic compounds, Anal. Chem., 77, 6989-6998, doi:10.1021/ac0506231, 2005.

Smith, D. and Španel, P.: Selected Ion Flow Tube Mass Spectrometry (SIFT-MS) for on-line trace gas analysis, Mass Spectrom. Rev., 24, 661-700, 2005.

Španl, P. and Smith, D.: Selected ion flow tube studies of the reactions of $\mathrm{H}_{3} \mathrm{O}^{+}, \mathrm{NO}^{+}$, and $\mathrm{O}_{2}^{+}$with several aromatic and aliphatic hydrocarbons, Int. J. Mass Spectrom., 181, 1-10, 1998.

Steeghs, M., Bais, H. P., de Gouw, J., Goldan, P., Kuster, W., Northway, M., Fall, R., and Vivanco, J. M.: Proton-transfer-reaction mass spectrometry as a new tool for real time analysis of rootsecreted volatile organic compounds in Arabidopsis, Plant. Physiol., 135, 47-58, 2004.

Talbot, R., Mao, H., and Sive, B. C.: Diurnal characteristics of surface level $\mathrm{O}_{3}$ and other important trace gases in New England, J. Geophys. Res., 110, D09307, doi:10.1029/2004JD005449, 2005.

Tan, C. Y. and Iglewicz, B.: Measurement-methods comparisons and linear statistical relationship, Technometrics, 41, 192-201, 1999.

Tani, A., Hayward, S., and Hewitt, C. N.: Measurement of monoterpenes and related compounds by proton transfer reaction-mass spectrometry (PTR-MS), Int. J. Mass Spectrom., 223/224, 561578, 2003.

Tani, A., Hayward, S., Hansel, A., and Hewitt, C. N.: Effect of water vapor pressure on monoterpene measurements using proton transfer reaction-mass spectrometry (PTR-MS), Int. J. Mass. Spectrom., 239, 161-169, 2004.

Warneke, C., de Gouw, J., Kuster, W. C., Goldan, P. D., and Fall, R.: Validation of atmospheric VOC measurements by proton-transfer-reaction mass spectrometry using a gaschromatographic preseparation method, Environ. Sci. Technol., 37, 2494-2501, 2003.
Warneke, C., McKeen, S. A., de Gouw, J. A., Goldan, P. D., Kuster, W. C., Holloway, J. S., Williams, E. J., Lerner, B. M., Parrish, D. D., Trainer, M., Fehsenfeld, F. C., Kato, S., Atlas, E. L., Baker, A., and Blank, D. R.: Determination of urban volatile organic compound emission ratios and comparison with an emissions database, J. Geophys. Res., 112, D10S47, doi:10.1029/2006JD007930, 2007.

Warneke, C., van der Veen, C., Luxembourg, S., de Gouw, J. A., and Kok, A.: Measurements of benzene and toluene in ambient air using proton-transfer-reaction mass spectrometry: calibration, humidity dependence, and field intercomparison, Int. J. Mass. Spectrom., 207, 167-182, 2001.

White, M. L., Russo, R. S., Zhou, Y., Ambrose, J. L., Haase, K., Frinak, E. K., Varner, R. K., Wingenter, O. W., Mao, H., Talbot, R., and Sive, B. C.: Are biogenic emissions a significant source of summertime atmospheric toluene in the rural Northeastern United States?, Atmos. Chem. Phys., 9, 81-92, doi:10.5194/acp9-81-2009, 2009.

White, M. L., Russo, R. S., Zhou, Y., Mao, H., Varner, R. K., Ambrose, J., Veres, P., Wingenter, O. W., Haase, K., Stutz, J., Talbot, R., and Sive, B. C.: Volatile organic compounds in northern New England marine and continental environments during the ICARTT 2004 campaign, J. Geophys. Res., 113, D08S90, doi:10.1029/2007JD009161, 2008.

Wyche, K. P., Blake, R. S., Willis, K. A., Monks, P. S., and Ellis, A. M.: Differentiation of isobaric compounds using chemical ionization reaction mass spectrometry, Rapid Commun. Mass Spectrom., 19, 3356-3362, 2005.

Zhao, J. and Zhang, R.: Proton transfer reaction rate constants between hydronium ion $\left(\mathrm{H}_{3} \mathrm{O}^{+}\right)$and volatile organic compounds, Atmos. Environ., 38, 2177-2185, 2004.

Zhou, Y., Varner, R. K., Russo, R. S., Wingenter, O. W., Haase, K. B., Talbot, R., and Sive, B. C.: Coastal water source of short-lived halocarbons in New England, J. Geophys. Res., 110, D21302, doi:10.1029/2004JD005603, 2005. 